

\title{
Bank Lending, Collateral, and Credit Traps in a Monetary Union
}

\author{
Giuseppe Corbisiero*
}

First version: March, 2016. This version: November, 2017.

\begin{abstract}
This paper investigates the transmission of non-standard monetary policy to firms' investment in a monetary union where financial frictions limit the access to external finance. The model incorporates a sovereign-banking nexus by assuming that sovereign default would generate a liquidity shock severely hitting domestic banks' balance sheet. I find that this feature crucially impairs the transmission mechanism, generating diverging responses and the risk of contagion across economies. In particular, I show that the liquidity injected into the risky country's banks results in financing the sovereign rather than boosting lending in some circumstances. Moreover, sovereign risk in one country can depress asset values, so generating spillover effects on lending throughout the monetary union via the collateral channel. The model sheds light on the troubled transmission of the ECB's policy measures to the economy of stressed countries during the sovereign debt crisis.
\end{abstract}

KEYWORDS: Bank Lending, Sovereign Risk, Monetary Policy, Crisis, Euro Area.

JEL Classification: E44, E52, F36, G01, G33.

\footnotetext{
${ }^{*}$ Central Bank of Ireland. Contact: giuseppe.corbisiero@centralbank.ie. This paper is based on a chapter from my $\mathrm{PhD}$ dissertation at the University of Mannheim. I am especially grateful to Michèle Tertilt and Klaus Adam for continuous advice and encouragement. I would also like to thank Benjamin Born, Antonio Ciccone, Francesco Paolo Conteduca, Peter Dunne, Florian Exler, Gabriel Fagan, Tullio Jappelli, Matthias Kehrig, Bernard Kennedy, Niccolò Lomys, Vera Molitor, Tommaso Oliviero, Marco Pagano, Nicola Persico, Henning Roth, Annalisa Scognamiglio, Saverio Simonelli, Emanuele Tarantino, Sweder van Wijnbergen as well as seminar participants at the Central Bank of Ireland, De Nederlandsche Bank, the University of Glasgow, the University of Mannheim, the University of Namur, and the University of Naples Federico II, and conference participants at the Petralia 2014 Applied Economics Workshop, the 2014 Frankfurt-Mannheim Macro Workshop, and the 11th CSEF-IGIER Symposium on Economics and Institutions for their helpful comments. Views expressed in this paper are mine and do not necessarily reflect those of the Central Bank of Ireland or the ESCB. All errors are mine.
} 


\section{Non-technical summary}

Since the beginning of the recent financial crisis, the ECB has responded to financial system impairments by complementing cuts in the policy interest rate with a wide range of non-standard measures, so injecting a large amount of liquidity at low cost. Nevertheless, bank lending hardly reacted, notably in countries where higher perceived risks of sovereign default emerged. At the same time, banks increased their domestic sovereign debt holdings to a much greater extent in stressed countries.

This paper provides a model to explain these stylized facts by studying the transmission of central bank liquidity injections to corporate lending in a monetary union. In this model, countries differ in sovereign risk, and firms' access to external finance can be constrained by financial frictions. The framework takes into account that the banking sector is very vulnerable to domestic sovereign risk, notably because of the high leverage of banks and their dependence on market confidence, which can disappear in a crisis. Specifically, I assume that the occurrence of sovereign default would generate a liquidity shock severely hitting a share of the country's banks.

Capturing the general equilibrium interplay between liquidity, financial frictions, firms' collateral, and lending, the model shows that the banking-sovereign nexus crucially impairs the monetary transmission mechanism. In particular, I show that lending responses to monetary policy across countries are asymmetric, with liquidity injections mainly financing the sovereign rather than boosting lending in the risky country. This is because the banking-sovereign nexus prevents banks from fully taking into consideration the risk of their sovereign; hence, they respond to liquidity injections by purchasing domestic sovereign debt, to the detriment of private lending. This theoretical mechanism can shed light on the troubled transmission of the ECB's policy measures to the economies of stressed countries during the euro sovereign debt crisis.

I also show that sovereign risk in one country generates negative spillover effects that, through the 'collateral channel', can depress lending throughout the monetary union. Specifically, the possibility of a liquidity shock due to sovereign risk can reduce the expected price of assets used as loan collateral; therefore, to the extent that asset markets are integrated across countries, sovereign risk can undermine debt capacity of firms even in economies that do not suffer from high sovereign risk. This transmission mechanism provides new testable implications briefly discussed in the paper.

The analysis suggests that reforming the financial architecture of the euro area, with the aim of weakening the link between a country's banking and the health of its public finances, could benefit the transmission of monetary policy. At the same time, a timely intervention in response to sovereign market turmoil would lessen banks' search for sovereign yields and allow a more effective stimulus to the real economy of stressed countries. Moreover, intervention in policy areas other than monetary policy - as fiscal policy - could more strongly stimulate investment, by circumventing a banking system overwhelmed by sovereign exposure. 


\section{Introduction}

To what extent can monetary policy boost firms' investment in a monetary union suffering from a recession and a sovereign debt crisis? Since the beginning of the recent financial crisis, the ECB and all major central banks in the world's developed economies have had to make recourse to new non-standard policy measures; this to overcome financial market impairments that were constraining the monetary transmission mechanism notwithstanding the reduction in the main policy interest rates (see, e.g., Fahr et al. 2011, and Mishkin 2011). Nevertheless, this could not prevent firms from suffering from a strong reduction in the availability of bank loans, particularly in euro area countries where higher perceived risks of sovereign default emerged since mid-2010.

This paper proposes a theory in which, contrary to the conventional approach, banks are exposed to their country risk. This generates a distortion of incentives to allocate bank capital, which can impair an effective transmission of accommodative monetary policy during recessions. Specifically, banks in the risky country will use the liquidity injected by the central bank to underwrite domestic sovereign debt, with investment levels not rising. Moreover, sovereign risk can depress collateral value, this way generating negative spillover effects on lending throughout the monetary union.

Figure 1 underlines the quantitative relevance of the issues analysed in this paper. The left panel shows bank loans to domestic non-financial corporations (NFCs), dividing euro area countries in two groups, 'periphery' - Greece, Ireland, Italy, Portugal, and Spain - and 'core' - Austria, Belgium, Finland, France, Germany, and Netherlands. From September 2008 to March 2015 bank loans increased by $5 \%$ in the core but reduced by $27 \%$ in the periphery. The series started diverging as sovereign spreads heightened: from September 2008 to June 2010, core and periphery experienced slight reductions, by $1 \%$ and 3\% respectively; by contrast, from June 2010 to March 2015, bank loans massively reduced by $25 \%$ in the periphery but increased by $6 \%$ in the core. Total credit to NFCs displays similar trends (see Figure 7 in the Appendix).

At the same time, sovereign bond portfolios of euro area banks started being less diversified and increasingly 'home biased'. A reversal in the process of financial integration in the euro area could find its rationale in core investors repatriating funds after a reassessment of the riskiness of their exposure to the periphery (see, e.g., Lane 2012). However, banks have increased their home exposure to a much greater extent exactly in those countries where high perceived risks of sovereign default emerged. From September 2008 to March 2015, banks' sovereign holdings have increased by $184 \%$ in the periphery and by $66 \%$ in the core. A strong divergence persisted from June 2010, with a $62 \%$ increase in the periphery vs. a $28 \%$ increase in the core (right panel of Figure 1). ${ }^{1}$

The theoretical analysis proposed here provides predictions in line with these stylised facts. The model builds upon the 'financial accelerator' literature, and more broadly on

\footnotetext{
${ }^{1}$ Figure 6 in the Appendix normalises the volumes in Figure 1 by total euro area government debt holdings and by total assets held by banks, showing very similar patterns.
} 
Bank loans to domestic NFC



Bank holdings of domestic sovereign debt

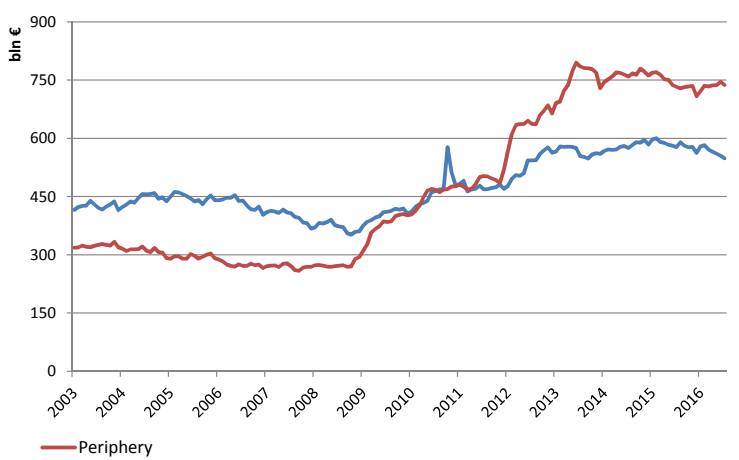

Figure 1: Loans to NFCs vs. Domestic Sovereign Holdings of Banks in the Euro Area

Left panel: monthly outstanding amounts of bank loans to domestic NFCs. Right panel: monthly outstanding amounts of bank holdings of domestic sovereign debt. Data source: ECB Statistical Data Warehouse.

the large literature arguing that collateral eases financial frictions and enhances firms' debt capacity and investment (Bernanke and Gertler 1989, Shleifer and Vishny 1992, Hart and Moore 1998, Bernanke et al. 1996, 1999, Kiyotaki and Moore 1997, Benmelech and Bergman 2012). In the model, firms need external funds to undertake a profitable project but, as in Kiyotaki and Moore (1997), banks cannot verify project returns; hence, firms need to pledge their assets as collateral, with the asset value constraining their debt capacity. Collateral price is endogenous and possibly function of the financial conditions of other industry participants (Benmelech and Bergman 2012, Shleifer and Vishny 1992). Non-standard measures are modeled in reduced-form as central bank injections of liquidity into commercial banks' balance sheet, and financial instability is captured by a liquidity shock forcing a share of firms to liquidate their assets (Benmelech and Bergman 2012).

Compared to the aforementioned literature, the framework is augmented so as to study a two-country monetary union, with governments issuing sovereign debt and exogenous probability of sovereign default. Moreover, the model includes a sovereign-banking nexus through the assumption that the occurrence of sovereign default would generate a liquidity shock hitting domestic banks' balance sheet.

To stress the role of these additional features, I compare the full model with a benchmark that abstracts from any sovereign-banking nexus. In the latter, the transmission of monetary policy is in line with the 'financial accelerator' literature. The impact of liquidity injections is twofold: first, the interest rate on loans (or 'lending rate') is reduced and this, in turn, expands the discounted expected price of collateral, i.e. $\frac{E(P)}{1+r}$, by reducing its denominator. Consequently, debt capacity of firms and corporate lending increase. Second, as a higher investment improves firms' cash flows, the demand for assets liquidated by firms in financial distress increases, boosting asset prices. Banks upgrade their expectations of the collateral value, $E(P)$, acknowledge a higher debt capacity of firms, and thus grant them even more loans.

Thanks to this virtuous interplay, the central bank can successfully offset the lending reduction during an economic downturn throughout the monetary union. However, as already shown by Benmelech and Bergman (2012), if the crisis is particularly severe 
- i.e. too many firms are forced to liquidate their assets - an excessive asset supply depresses liquidation prices, and corporate lending will be constrained at a sub-optimal level, regardless of the strength of the central bank intervention.

The full model introduces a sovereign default shock hitting domestic banks strongly enough to force a share of them into bankruptcy. This feature generates a novel mechanism according to which the transmission of monetary policy can result impaired, with diverging responses and the risk of contagion across economies. For ease of exposition, suppose that there is a positive probability of sovereign default in country $R$, but not in country $S$; moreover, suppose that the share of domestic banks forced into bankruptcy by sovereign default equals one. ${ }^{2}$ In Section 3, I show that there is a possibly large range of liquidity within which the transmission mechanism described above results impaired.

The intuition is as follows. Expected profits of banks in country $R$ do not increase with future returns that realise at the same time as sovereign default: this is because the occurrence of sovereign default would force banks into bankruptcy (and zero profit, being protected by limited liabilities) anyway. But this implies that, at time- 0 , banks do not internalise the risk component contained in the yields on domestic sovereign bonds. Therefore, when allocating their capital, banks do not differentiate between firm loans, guaranteeing repayment up to the collateral value, and domestic sovereign debt with a possibly higher risk profile.

Suppose the central bank injects liquidity in the system to stimulate investment. Yields paid by country $R$ 's sovereign debt remain high, because foreign investor require compensation for its risk. Banks can underwrite sovereign bonds paying high yields, whose risk component they do not internalise. For this reason, from a certain level onward, liquidity injections will end up financing the sovereign, with lending rates not responding. Absent a lending rate reduction, the collateral constraint prevents debt capacity of firms from increasing and investment levels do not rise. By contrast, monetary policy remains incessantly effective in stimulating lending in the safe country. This theoretical mechanism can shed light on the troubled transmission of the ECB's policy measures to the economies of stressed countries during the euro sovereign debt crisis.

Additionally, sovereign risk can generate negative spillover effects on lending throughout the monetary union, by depressing the value of assets used as loan collateral. This second mechanism is due to the fact that banks in country $S$ can rationally anticipate that, if the government in country $R$ defaults in the next period, domestic firms holding bank deposits will have less funds to purchase liquidated assets. This fall in the demand can lower the asset price, which would lead banks to update their expectations of the value of collateral and downgrade debt capacity of firms today, even in the safe country. In some circumstances, the central bank is not able to offset this contraction in lending, regardless of the monetary policy stance. Therefore, the monetary transmission mechanism becomes impaired even in economies that are not directly subject to high sovereign risks. This transmission mechanism provides new testable implications briefly discussed below.

\footnotetext{
${ }^{2}$ Section 3 characterises results for this share assuming any value between 0 and 1 .
} 
In models that neglect financial frictions, monetary policy generally stimulates investment for the usual cost-of-capital reasons. By contrast, this paper focusses on the role of financial frictions and the effect of monetary policy on firms' debt capacity, in line with the aforementioned 'financial accelerator' literature. ${ }^{3}$ Within this modelling framework, Benmelech and Bergman (2012) have already shown that credit trap equilibria can occur, with banks choosing to hoard liquidity in spite of the monetary expansion. ${ }^{4}$ Compared with this literature, this paper shows that the introduction of sovereign risk and a banksovereign nexus, in an augmented multi-country framework, leads to a novel mechanism distorting the allocation of bank capital and generating predictions in line with lending figures of euro area countries during the crisis.

This paper adds to a vast recent literature that addresses bank exposures and sovereign stress during the euro sovereign debt crisis. According to the "moral suasion" hypothesis, a close connection with government can explain banks' propensity to support public issuance in times of stress (Uhlig 2014, Battistini et al. 2014, Crosignani 2015, Ongena et al. 2016). A different hypothesis suggests that undercapitalised banks in the periphery followed a "carry trade" strategy, purchasing distressed, high-yield public debt to gamble for resurrection (Acharya and Steffen 2015, Acharya et al. 2015, and Ari 2016). Altavilla et al. (2016) provide a nested specification to assess empirically the "moral suasion" and the "carry trade" hypotheses. In the sovereign-banking feedback loop models of Gennaioli et al. (2014), Bocola (2016), Brunnermeier et al. (2016), and Fahri and Tirole (forthcoming), sovereign risk negatively affects the economy by undermining the balance sheet of domestic banks. In Broner et al. (2014), creditor discrimination and crowding-out effects reduce growth and welfare, possibly leading to self-fulfilling crises.

As regards this literature, the mechanism of this paper mainly relates to the "carry trade" hypothesis - to the extent that a bank, because of a variable outside its control (in this paper, the ex-ante exposure to domestic sovereign risk; in the latter, the ex-ante bank undercapitalisation), has incentive to gamble for the resurrection of the domestic sovereign, regardless of its default risk. The reasons behind the choice of incorporating a simple, non microfounded, sovereign-banking nexus are as follows. First and foremost, it allows closed form solutions within a general equilibrium model in which both the financial friction and the collateral market are fully microfounded - this way making it possible to rigorously analyse the interplay between liquidity injections, firms' investment and endogenous dynamics in collateral values. Second, while the aforementioned literature focusses on bank exposures and/or strategic default, my analysis has as ultimate goal the mechanism through which monetary policy transmits to the real economy. The result is a simple, but powerful mechanism, which generates diverging lending responses across

\footnotetext{
${ }^{3}$ Recent papers providing evidence in support of the role of financial frictions include, e.g., Benmelech and Bergman (2011), Hertzel and Officer (2012), Ortiz-Molina and Phillips (2014), Adelino et al. (2015). See Shleifer and Vishny (2011) for a review of the literature on fire sales in macroeconomics and finance.

${ }^{4}$ Alternative theoretical approaches that also focus on the role of financial frictions for the emergence of credit traps are provided by, e.g., Shleifer and Vishny (2010), Bebchuk and Goldstein (2011), Perri and Quadrini (2011), Buera and Nicolini (2014), and Gorton and Ordoñez (2014).
} 
countries that only differ in sovereign risk, and highlights a novel transmission mechanism of sovereign stress in a monetary union through endogenous dynamics in collateral values.

To neatly identify the main mechanism, in the model the two economies only differ in sovereign risk. This way, this theory abstracts from the possibility that a stronger decline in business opportunities in the periphery could be the main reason behind diverging responses in lending during the crisis. Without questioning the relevance of this hypothesis, evidence suggests that credit supply factors have been crucial determinants of the observed decline in investment in the periphery, where banks with larger sovereign exposures reduced lending and charged higher interest rates to a greater extent (De Marco 2014, Popov and van Horen 2015, Acharya et al. 2015, and Altavilla et al. 2016) .

The model does not capture the use of government bonds as collateral to obtain central bank liquidity (see, e.g., Crosignani et al. 2016, and van der Kwaak 2017). For the aim of this paper, this would be a relevant shortcoming if periphery banks pledged government bonds as collateral for central bank liquidity subsequently used to increase lending ('crowding-in'). However, the evidence presented above points more to a shift in bank portfolio composition owing to a search for high sovereign yields ('crowding-out').

The rest of this paper is organised as follows. Section 2 presents the model setup. Section 3 describes firstly the monetary transmission in the benchmark case, and then studies the impact of the sovereign-banking nexus on the effectiveness of monetary policy. Section 4 concludes.

\section{$2 \quad$ Model setup}

In a stylised 3-period general equilibrium framework, two countries $(R$ and $S$ ) constitute a monetary union. Each country is populated by firms, commercial banks, and a government issuing sovereign bonds that do not repay in the next period with an exogenous probability. The following features constitute the building blocks of this model.

Financial frictions and firms' access to external finance. As in Kiyotaki and Moore (1997), lenders cannot verify returns on firms' projects, which implies that debt cannot exceed the value of assets pledged as collateral ("collateral-in-advance" constraint).

Non-standard monetary policy. As in Benmelech and Bergman (2012), the central bank controls the total liquidity in the system through non-standard measures, modeled in reduced-form as liquidity injections into commercial banks' balance sheet.

Market for funds. Absent any segmentation in the market for funds, the law of one price would imply equal lending rates across countries; moreover, deposits in the riskier banking system would be entirely moved to banks in the safer country. To prevent the model from displaying such unrealistic features, I assume two types of segmentation: first, banks face an operating cost of lending funds abroad, which allows a band within which lending rates can differ across countries; second, firms cannot deposit their wealth in foreign banks. 
Market for firms' asset. Asset price dynamics capture Shleifer and Vishny's hypothesis (1992) that fire sales due to financial distress depress debt capacity of other industry participants. As in Benmelech and Bergman (2012), a liquidity shock, capturing the crisis' severity, forces a share of firms to liquidate their assets.

Banking-sovereign nexus. There is a positive probability that, at least in one country, sovereign default will occur at time-1. Making their time-0 investment decisions, banks anticipate that the occurrence of sovereign default in the next period will force a share of domestic banks into bankruptcy, regardless of their portfolio composition.

The rest of this section describes the model setup in details. Figure 2 comprehensively summarises the timing of events. ${ }^{5}$

\section{$2.1 \quad$ Firms' problem}

Each country is populated by a continuum of firms $\mathcal{B}_{\mathbf{i}}$ of measure one, each endowed with an identical preexisting asset and different initial wealth levels $A$, which are i.i.d. draws according to probability measure $\mathbf{P}_{A}$ over $[0, I]$, with associated cumulative distribution function $F(A)$. Each firm can undertake a project, which requires a monetary investment of $I$ at time- 0 , and generates returns $X_{1}$ at time- 1 and $X_{2}$ at time-2, with $I<X_{1}<X_{2}$. Firms can borrow from domestic or foreign banks to finance the project. For convenience, a firm's borrowing requirement $B$ is defined as the difference between the cost of the project and the firm's initial wealth, $B \equiv I-A$. Let $F(B)$ be the cumulative distribution function according to which firms' borrowing requirements $B$ are distributed over the interval $[0, I]$. If firms do not obtain sufficient funds from banks, they can deposit their initial wealth in domestic banks, ${ }^{6}$ earning a return determined by the equilibrium interest rate.

As in Benmelech and Bergman (2012), firms face an idiosyncratic liquidity shock: at time-1, a fraction $\gamma_{i}$ of country $i$ 's firms, whose identity is ex-ante unknown, are forced to liquidate their asset and to consume all their available wealth. A higher $\gamma_{i}$ proxies for a higher aggregate liquidity shock hitting the economy or, in other words, for a more severe impact of the crisis.

The price of the liquidated asset, $P$, is endogenously determined in a union-level market, whose suppliers are firms hit by the liquidity shock and operators are the others. Purchasing an additional asset unit generates a return $Y>0$ at time-2, while holding it generates a return $X_{2}^{\prime}>Y$ at time-2 (the latter implies that firms do not voluntarily liquidate assets at time-1). The return guaranteed by an additional asset does not exceed the project's cost, $Y<I$ (as the asset price is bounded from above by $Y$, this inequality implies that the collateral constraint binds at least for some firms).

\footnotetext{
${ }^{5}$ As time is discrete, in each period all events take place simultaneously.

${ }^{6}$ This avoids that country $R$ 's bank deposits are entirely moved abroad, but also represents the fact that the vast majority of firms in the euro area operate with domestic banks (NFCs deposits in foreign banks have been consistently around $7 \%$ over the last decade, absent significant variations during the crisis: see 'balance sheet items', Statistical Data Warehouse, ECB).
} 


\begin{tabular}{lcc}
\multicolumn{1}{c}{$t=0$} & $t=1$ & \multicolumn{1}{c}{$t=2$} \\
\hline CB liquidity injection & Returns on investment: & Returns on investment: $X_{2}$ \\
Issue of government bonds & $X_{1}$ or $(1+r) A$ & Returns on asset holding: \\
Bank investment decision & Firms pay back debt & $Y, X_{2}^{\prime}$ \\
Firm investment decision & $\gamma_{i}$ firms liquidate asset: & Bankrupt banks' liquidation: \\
& market for collateral & $\alpha(1+r) A$ \\
& If sovereign default: & \\
& $\delta$ banks go bankrupt &
\end{tabular}

Figure 2: Timing of Events

Given a lending rate $r_{i}^{f}$ and a deposit rate $r_{i}^{d}$, a country $i$ 's firm with borrowing requirement $B$ obtains by undertaking the project the time-0 expected payoff:

$$
\gamma_{i}\left[X_{1}+E(P)-\left(1+r_{i}^{f}\right) B\right]+\left(1-\gamma_{i}\right)\left[X_{2}+\left(X_{1}-\left(1+r_{i}^{f}\right) B\right) Y E\left(\frac{1}{P}\right)+X_{2}^{\prime}\right]
$$

With probability $\gamma_{i}$, at time- 1 the firm is hit by a liquidity shock, forced to liquidate assets and consume its wealth, constituted by the return on project, $X_{1}$, plus the expected liquidation value of the asset, $E(P)$, minus the bank loan repayment, $\left(1+r_{i}^{f}\right) B$. With probability $1-\gamma_{i}$, the firm can continue its business until time- 2 , when the project generates $X_{2}$ and the asset generates $X_{2}^{\prime}$. In this case, the firm can use its time- 1 wealth to purchase assets, with expected price $E(P)$ and time-2 return $Y$.

Alternatively, a firm can deposit its initial wealth $I-B$ in the banks, for an expected payoff given by: ${ }^{7}$

$$
\gamma_{i}\left[\left(1+r_{i}^{d}\right)(I-B)+E(P)\right]+\left(1-\gamma_{i}\right)\left[\left(1+r_{i}^{d}\right)(I-B) Y E\left(\frac{1}{P}\right)+X_{2}^{\prime}\right] .
$$

Also in this case, with probability $\gamma_{i}$ a liquidity shock forces the firm to consume its time-1 wealth, constituted by the gross return on deposits, $\left(1+r_{i}^{d}\right)(I-B)$, and the expected liquidation value of the asset, $E(P)$. With probability $1-\gamma_{i}$, the firm can continue its business until time-2, when the asset generates $X_{2}^{\prime}$, and the additional assets bought in the previous period guarantee a gross return equal to $\left(1+r_{i}^{d}\right)(I-B) Y E\left(\frac{1}{P}\right) .^{8}$

Financial frictions require that the financial contract is incentive compatible, and this can limit the firm's ability to obtain funds from banks and hence to undertake the project. Specifically, the amount of obtainable funds must satisfy a collateral-in-advance constraint (as characterised in Section 3.1.1 and 3.2.1).

\subsection{Banks' problem}

Each economy includes a large number $n$ of competitive commercial banks, all identical. At time-0, bank liabilities are given by firms' deposit, $D$, plus the bank's share of liquidity

\footnotetext{
${ }^{7}$ Banks' exposure to sovereign risk (i.e. $\delta>0$ ) modifies the expected return on deposits but not the expected payoff from undertaking the project: see Appendix A for more details.

${ }^{8}$ Firms can only choose between the project and bank deposit; however, the risk of bank bankruptcy in the full model can create incentives to keep cash to purchase liquidated assets at time-1. As a robustness check, the proof of Lemma 3 considers the case in which firms can also keep initial wealth.
} 
injected by the central bank, $l=\frac{L}{n}$; assets are composed of the loans granted to firms demanding funds, plus government bonds purchased and bank's deposit in the central bank (pre-existing compulsory reserves, Res, plus elective deposits, $C$ ).

Given gross returns $R_{i}$ on the various investments $X_{i}$ (domestic and foreign lending, domestic and foreign government bonds), and the return on deposits, $R_{D}$, banks maximise their expected time-1 payoff:

$$
E\left(\Pi_{1}\right)=\sum_{i} R_{i} X_{i}+R e s+C-R_{d} D-l,
$$

where gross returns include risk and cost components of investments - e.g., $R_{g_{D}}=(1-$ $\left.\rho_{D}\right)\left(1+r^{g_{D}}\right)$, where $\rho_{D}$ is the probability of default and $r^{g_{D}}$ the nominal yield of domestic sovereign debt, and $R_{f_{F}}=1+r^{f_{F}}-c$, with $r^{f_{F}}$ rate and marginal cost $c$ of lending to foreign firms. A zero interest rate applies on operations with the central bank. The bank maximises (3) at time- 0 over the decision variables $X_{i}$ and $C$, subject to the constraint:

$$
\sum_{i} X_{i}+C \leq D+l
$$

Moreover, each loan granted must satisfy the collateral-in-advance constraint (as characterised in Section 3.1.1 and 3.2.1).

The sovereign-banking nexus is introduced through the following assumption.

Assumption: sovereign default shock If sovereign default occurs at time-1, it generates a liquidity shock $S$ that hits the balance sheet of a fraction $\delta \in(0,1]$ of domestic banks. $S$ exceeds the bank's net assets, regardless of its portfolio composition.

As firms are subject to a shock capturing the effects of the financial crisis, banks are subject to a shock that captures the effects of the sovereign debt crisis (as for firms, the identity of banks hit by the shock is ex-ante unknown). If sovereign default occurs in country $i$ at time-1, domestic banks are subject to the following idiosyncratic shock:

$$
\sigma= \begin{cases}S, & \text { with probability } \delta \\ 0, & \text { with probability } 1-\delta\end{cases}
$$

Conditional on the occurrence of sovereign default in the next period, the present expected payoff of a domestic bank is given by:

$$
E\left(\Pi_{1} \mid \operatorname{sdef}_{D}=1\right)=\max \left\{\sum_{i} R_{i} X_{i}+R e s+C-R_{d} D-l-\delta S, 0\right\},
$$

where the max operator applies because of banks' limited liabilities.

The 'sovereign default shock' assumption implies that:

$$
S \geq \sum_{i} R_{i} X_{i}+R e s+C-R_{d} D-l, \forall X \forall C,
$$

which, in turn, implies that:

$$
E\left(\Pi_{1} \mid \operatorname{sdef}_{D}=1, \sigma=S\right)=0,
$$

that is, the negative shock is sufficiently large to force into bankruptcy banks hit. ${ }^{9}$

\footnotetext{
${ }^{9}$ The share $\delta$ of banks hit by the sovereign default shock can assume any value in the interval $(0,1]$
} 
Given equations (5), (6) and (7), time-1 banks' expected payoff is now given by: ${ }^{10}$

$$
E\left(\Pi_{1}\right)=\left(1-\rho_{D} \delta\right)\left(\sum_{i \neq g_{D}} R_{i} X_{i}+R e s+C-R_{d} D-l\right)+R_{g_{D}} X_{g_{D}} .
$$

The 'sovereign default shock' captures, in reduced form, systemic developments in the financial system that are likely to follow sovereign default. For instance, the disappearence of the deposit insurance scheme provided by the government, as well as of the implicit sovereign back-stop to domestic banks, can cause a bank run irreparably deteriorating finances of (at least a share of) banks, regardless of their portfolio composition.

A large part of the literature on sovereign default assumes that governments can selectively default on foreign bondholders and protect domestic investors; according to this hypothesis, domestic banks should not suffer direct losses from the default of the sovereign. This paper takes the opposite perspective, assuming instead that sovereign default would firstly and mainly hit domestic banks (in the spirit, e.g., of Gennaioli et al. 2014). First, this approach can better rationalise the significant consequences for the domestic economy and financial system observed during several past episodes of sovereign default. Second, it is consistent with the methodology in use at credit rating agencies, which rarely rate banks above their sovereign because banking - a leveraged industry that strongly relies on market confidence - is considered to be more likely than any other industry to be directly or indirectly affected by domestic sovereign default (Standard \& Poor's 2004, 2011).

While $\rho$ interprets the probability of sovereign default, $\delta$ - the share of domestic banks hit by the sovereign default shock - can reflect the strength of the sovereign-banking nexus.

In the model, creditor firms of bankrupt banks do not have immediate access to recoverable funds, i.e. cannot use them to purchase liquidated assets at time-1. This assumption captures the hypothesis that, through the banking system, the sovereign default shock also affects liquidity available to the domestic demand for liquidated assets. For simplicity, I do not explicitly model a market for distressed banks' assets, assuming instead that at time-2 creditor firms recover a fraction of the gross return on deposit they would have obtained in case of no bankruptcy, i.e. $\alpha R_{d}(I-B) .{ }^{11}$

\subsection{Governments}

In each country there is a government issuing sovereign debt in fixed supply, $G_{i}>0$. The model abstracts from strategic default considerations, hence it does not assign an objective function to governments. There is instead an exogenous probability, $\rho_{i}$, that country $i$ 's government is forced to declare insolvency, with $\rho_{R}>\rho_{S} \geq 0$. In this case, the government does not repay bondholders and the sovereign default shock, $S$, realises.

\footnotetext{
without qualitatively changing the results - which lessens the strength of this simplifying assumption.

${ }^{10}$ Note that this formulation of the problem implicitly assumes that, if $\operatorname{sdef}_{i}=1$ and $s=0$, bank reserves $R$ are sufficient to compensate for potential losses due to no repayment of sovereign bonds.

${ }^{11} \alpha$ can assume any value in the interval $(0,1)$ without qualitatively changing the results, i.e. the mechanism requires that sovereign default jeopardises bank liquidity, but not the destruction of resources.
} 
I assume that sovereign risks are uncorrelated; this is trivially without loss of generality in the most relevant case that the monetary union is composed of a risky country and a safe one - reflecting 'stressed' countries and 'core' ones of the euro area. ${ }^{12}$

Outside the monetary union, there are international investors willing to underwrite sovereign bonds at an interest rate just compensating their risk, $r_{I N T}^{g_{i}}=\frac{\rho_{i}}{1-\rho_{i}}$. This demand establishes an upper-bound on sovereign yields that rule out equilibria with no real investment. Whilst such upper-bound is important, the generality of results does not depend on the level specifically assumed. ${ }^{13}$

\subsection{Central bank}

The central bank directly injects liquidity into commercial banks' balance sheet (Benmelech and Bergman 2012), equally across countries and banks - i.e., for an aggregate level of $2 L, L$ is the liquidity injection in each country, and $l=\frac{L}{n}$ the liquidity injected in each single bank. However, banks can deposit back in the central bank the liquidity injected, without incurring any cost (see the banks' problem). This provides a quite direct interpretation of policy measures such as the ECB's two 3-year LTROs undertaken in 2011-12. These operations made central bank liquidity available to all banks in the euro area, but funds were only allotted to those who applied for them.

To analyze the effects of non-standard measures over a wider range of policy intervention, an objective function is not assigned to the central bank, and the model considers instead the equilibrium lending response for any level of liquidity injected.

\section{Results}

\subsection{Benchmark case: no sovereign-banking nexus}

To underline how the sovereign-banking nexus impacts the monetary transmission mechanism, I compare the full model with a benchmark in which sovereign default does not hit domestic banks' balance sheet. In the latter, monetary policy only encounters the limitation shown in Benmelech and Bergman (2012). If the share of firms forced to liquidate assets is too large, an excess supply prevents asset prices from increasing beyond a certain level. Hence, bank lending is sub-optimal, in spite of the monetary policy stance. Concerning the transmission of monetary policy across countries, however, Proposition 1 shows that lending responses are equal, regardless of differences in sovereign default risk and/or in the magnitude of the liquidity shock hitting the two economies.

In the following, first, I consider the asset liquidation value as exogenous; thereafter, I include an endogenous market for collateral, so as to take into consideration the full interplay between liquidity injections, collateral price, and lending.

\footnotetext{
${ }^{12}$ If both countries suffer from a positive sovereign risk, results remain valid, but reduced in magnitude, for a positive, smaller than one correlation; they are amplified for a negative correlation.

${ }^{13}$ If $r_{I N T}^{g_{i}}>\frac{\rho_{i}}{1-\rho_{i}}$, lending rates shifts upward both in the benchmark and in the full model within a certain liquidity range - without affecting the comparison between the two, hence the generality of results.
} 


\subsubsection{Equilibrium for a given asset price}

Financial frictions and firms' demand for funds A firm with initial wealth $A$ needs to borrow an amount $B=I-A$ to undertake the project, but its debt capacity is limited, given that bank claims on project returns cannot be enforced. Each firm is endowed with a real asset that can be pledged as loan collateral, with the bank able to foreclose on it in case of no debt repayment. Given the returns scheme, there are positive values of debt such that the threat of liquidation exerted by the creditor bank induces the firm to repay at time-1, and the parties can write an incentive compatible financial contract. However, banks anticipate that no repayment exceeding the asset liquidation value $P$ will take place in equilibrium; ${ }^{14}$ then, at time- 0 a financial contract is optimal if and only if it specifies a repayment smaller than or equal to the liquidation price of asset: $B\left(1+r^{f}\right) \leq P .{ }^{15}$ Hence, the maximum amount of funds that a firm can borrow at time-0 equals:

$$
B \leq \frac{P}{1+r^{f}} .
$$

Firms differ in their initial wealth, and only those with borrowing requirement satisfying the 'collateral-in-advance constraint' (9) can obtain sufficient funds to undertake the project. Whether they do so also depends on the expected return on deposits.

Given a country $i$ 's lending rate $r_{i}^{f}$ and a deposit rate $r_{i}^{d}$, a firm with borrowing requirement $B$ will prefer to undertake the project if the following condition - the 'investment participation constraint' (IPC) - is satisfied:

$$
\begin{aligned}
& \gamma\left[X_{1}+P-\left(1+r_{i}^{f}\right) B\right]+(1-\gamma)\left[X_{2}+\left(X_{1}-\left(1+r_{i}^{f}\right) B\right) \frac{Y}{P}+X_{2}^{\prime}\right] \\
& \geq \gamma\left[\left(1+r_{i}^{d}\right)(I-B)+P\right]+(1-\gamma)\left[\left(1+r_{i}^{d}\right)(I-B) \frac{Y}{P}+X_{2}^{\prime}\right] .
\end{aligned}
$$

The left hand side represents the expected payoff from undertaking the project, and right hand side the one from depositing wealth in the banks; rearranging terms, we obtain:

$$
X_{1}\left[\gamma+(1-\gamma) \frac{Y}{P}\right]+X_{2}(1-\gamma) \geq\left[B\left(r_{i}^{f}-r_{i}^{d}\right)+I\left(1+r_{i}^{d}\right)\right]\left[\gamma+(1-\gamma) \frac{Y}{P}\right] .
$$

From equation (11), we find that if the lending rate and the deposit rate are equal, i.e. $r_{i}^{f}=r_{i}^{d}$, the IPC does not depend on the firm's borrowing requirement $B$. On the other side, if $r_{i}^{f}>r_{i}^{d}$, the IPC is tighter as $B$ is higher.

From the banks' point of view, operating with domestic firms is profit maximizing only if the lending rate is at least as big as the deposit rate, $r_{i}^{f} \geq r_{i}^{d}$. This must hold in equilibrium; hence, banks accept all deposits and incentive compatible loan applications from domestic firms.

Furthermore, as banks are perfectly competitive, in equilibrium the lending rate and

\footnotetext{
${ }^{14}$ Following Benmelech and Bergman (2012), I assume that at time-1 the firm has all the bargaining power in renegotiating its debt obligation with the bank. This implies that the firm will always bargain down its repayment to the bank's outside option, that exactly equals the liquidation value of the asset $P$.

${ }^{15}$ See, e.g., Hart and Moore $(1994,1998)$ for more details. Note that, as $P$ is considered exogenous, there is no expected value operator.
} 
the deposit rate coincide, i.e. $r_{i}^{f}=r_{i}^{d}=r_{i}$; foreign loans must include instead the cost of foreign lending, i.e. $r_{i}^{f_{F}}=r_{i}+c$. Lemma 1 below shows that, in equilibrium, firms only demand domestic loans, and the relevant lending rate coincides with the domestic one, $r_{i}^{f}=r_{i}^{f_{D}}, \forall i$. Hence, $r^{f}=r$. This allows us to further simplify the IPC as follows:

$$
r \leq \frac{X_{1}}{I}+\frac{(1-\gamma) X_{2}}{\left[\gamma+(1-\gamma) \frac{Y}{P}\right] I}-1=\bar{r} .
$$

The threshold $\bar{r}$ determines whether it is convenient to undertake the project and, together with condition (9), allows us to obtain the effective private demand for funds in each country. If $r>\bar{r}$, all firms find it optimal to deposit wealth in the banks. By contrast, if $r \leq \bar{r}$, undertaking the project maximises firms' profit. Nevertheless, the collateral-inadvance constraint (9) limits the debt capacity of firms. Firms with binding collateral constraint cannot collect sufficient funds to undertake the project, i.e. $A+\frac{P}{1+r}<I$; hence, they deposit their wealth in the banks. All firms for which the collateral constraint does not bind will instead demand loans, for a total amount equal to:

$$
D_{i}^{i}\left(r_{i}, r_{j}\right)=\int_{0}^{P /(1+r)} B d F(B)
$$

where $D_{i}^{i}$ indicates the total demand from country $i$ 's firms (lower index) for funds supplied by country $i$ 's banks (upper index).

Governments' demand for funds International investors are willing to purchase sovereign bonds at an interest rate $r_{I N T}^{g_{i}}=\frac{\rho_{i}}{1-\rho_{i}}$. At this rate, the expected return on sovereign bonds is zero. As long as the lending rate is positive, the expected return on firm loans is positive and banks do not underwrite sovereign debt, which is totally purchased by foreign investors. By contrast, if the total liquidity is sufficiently large to lead to a zero lending rate, banks may purchase sovereign bonds in equilibrium (Lemma 1).

Banks' supply of funds and equilibrium Domestic banks' supply of funds is constituted by firms' deposits plus liquidity injected by the central bank, $L$. If $r \leq \bar{r}$, the firms' IPC is satisfied. All domestic firms with borrowing requirement $B \leq P /(1+r)$ undertake the project, while those with borrowing requirement $B>P /(1+r)$ deposit their wealth in the domestic banks. Aggregating over banks, the total supply of funds in each country is given by:

$$
S_{i}\left(r_{i}, r_{j}\right)=L+\int_{P /(1+r)}^{I}(I-B) d F(B) .
$$

The following lemma characterises the equilibrium on the market for funds for any exogenous asset liquidation value, $P$, and aggregate liquidity injection, $L$.

Lemma 1 Assume $\delta=0$. Given an exogenous asset value $P$, in equilibrium:

(i) The interest rate on government $i$ 's bonds satisfies $r_{i}^{g}=\frac{\rho_{i}}{1-\rho_{i}}, \forall i$. Country $i$ 's bank purchases of government bonds can be positive only if $r_{i}^{f}=0, \forall i$. 
(ii) Lending and deposit rates are equal and coincide across countries, $r_{i}^{f}=r_{i}^{d}=r_{i}=r$, $\forall i$. Country $i$ 's banks do not lend funds to country $j$ 's firms, $\forall i, j$.

(iii) For any liquidity level L, the firms' IPC (10) does not bind in both countries. Firms with borrowing requirement $B \leq \frac{P}{1+r}$ undertake the project, while the others deposit their wealth in the banks.

(iv) There is a threshold $L_{\max }$ such that lending rates equal zero in both countries. Up to that threshold, an increase in $L$ constantly reduces lending rates.

Proof See Appendix B.

Liquidity injections expand the supply of funds and reduce the lending rate: the collateral-in-advance constraint relaxes, and more firms invest. Sovereign risks have no effect on the transmission of monetary policy to corporate lending, regardless of crosscountry differences. As a loan does not exceed the asset price, collateral guarantees full repayment of the loan, regardless of the firms' liquidity risk. By contrast, country $i$ 's sovereign bonds do not repay at time-1 with probability $\rho_{i}$. Hence, banks underwrite them only if their yield guarantees at least the loans' expected return, $r_{i}^{g} \geq \frac{r+\rho_{i}}{1-\rho_{i}}$.

\subsubsection{Equilibrium with endogenous asset price}

As a collateral constraint applies, the effects of liquidity on asset price dynamics crucially affect the transmission of monetary policy to lending. Before analyzing such effects, it is convenient to provide a definition of the equilibrium in the economy analyzed when the asset price is endogenous.

Equilibrium definition An equilibrium in the economy described in Section 2 is a vector $\left\{L, r_{R}, r_{S}, r_{R}^{g}, r_{S}^{g}, P\right\}$ such that:

(i) Firms optimally make their borrowing and investment decisions, given lending rates $r_{R}$ and $r_{S}$, and the asset liquidation value $P$;

(ii) Banks optimally make their lending choices knowing that, given the time-1 realisation of shocks $\{\sigma\}$, firms will repay no more than the asset liquidation value $P(\sigma)$;

(iii) Lending rates $r_{R}$ and $r_{S}$, and sovereign yields $r_{R}^{g}$ and $r_{S}^{g}$, are equilibrium values such that, at time-0, markets for loanable funds and for sovereign bonds clear;

(iv) Given the time-1 realisation of the sovereign default shock $\sigma, P=\mathbf{P}(L, \sigma)$ is an equilibrium price such that the market for liquidated assets clears.

The equilibrium requirements (i) to (iii) simply state that firms and banks optimise in their choices, conditional on the financial contract being optimal; interest rates adjust in equilibrium such that markets for loans and for sovereign bonds clear - as characterised by the market clearing conditions provided in Section 3.1 above. The requirement (iv) takes into consideration the endogenous market for liquidated assets, analyzed in this section. 
In the full model, the price of asset is stochastic and function of $\sigma$, the time- 1 realisation of the sovereign default shock. In the benchmark, it is a deterministic function of the liquidity injected by the central bank and can be derived as follows. At time-1, the share of firms hit by the liquidity shock sell their asset, which can be bought by other firms. Purchasing an additional asset generates return $Y$ at time-2. Assets are freely traded across the monetary union countries. Perfect competition between bidders would lead to a price equal to the asset return $Y,{ }^{16}$ but firms are liquidity constrained; hence, depending on their time-1 wealth, the equilibrium asset price can be strictly lower than $Y$.

For each country, define $B_{i}$ as the borrowing requirement of the marginal borrowing firm, $B_{i} \equiv \frac{E(P)}{1+r_{i}}$, and the vectors $\underline{B} \equiv\left(B_{R}, B_{S}\right), \underline{r} \equiv\left(r_{R}, r_{S}\right)$. Total time- 1 wealth of firms spared by the liquidity shock equals:

$$
Q(\underline{B}, \underline{r})=\sum_{i}\left(1-\gamma_{i}\right)\left[\int_{0}^{\frac{E(P)}{1+r_{i}}}\left(X_{1}-B\left(1+r_{i}\right)\right) d F(B)+\int_{\frac{E(P)}{1+r_{i}}}^{I}(I-B)\left(1+r_{i}\right) d F(B)\right],
$$

which is the cross-country sum of the wealth of firms who invested in the project (first integral in parenthesis) and the wealth of those who deposited in the banks (second integral in parenthesis). Consequently, the aggregate demand for assets is:

$$
D(P ; \underline{B}, \underline{r})=\left\{\begin{array}{cc}
{\left[0, \frac{Q(\underline{B}, \underline{r})}{Y}\right]} & \text { if } P=Y \\
\frac{Q(\underline{B}, \underline{r})}{P} & \text { if } P \in(0, Y)
\end{array}\right.
$$

The total supply of asset is simply $\gamma_{R}+\gamma_{S}$. By market clearing, $D(P ; \underline{B}, \underline{r})=\gamma_{R}+\gamma_{S}$, and the equilibrium asset price is:

$$
\mathbf{P}(\underline{B}, \underline{r})=\min \left\{\frac{Q(\underline{B}, \underline{r})}{\gamma_{R}+\gamma_{S}}, Y\right\} .
$$

Define $\gamma \equiv \frac{\gamma_{R}+\gamma_{S}}{2}$. Proposition 1 shows that, if $\gamma$ if sufficiently small, a sufficient liquidity injection will enable $P^{*}=Y$. In this case, banks lend the whole liquidity injected up to $L_{\max }$, threshold at which rates are zero and lending is maximal in each country, i.e. $\int_{0}^{Y} B d F(B)$. Monetary policy is fully effective: as the central bank injects liquidity, the interest rate is reduced, relaxing the collateral constraint. More firms invest, expanding time-1 wealth used to buy liquidated assets: the asset price increases, which relaxes further the collateral constraint. Anticipating this dynamic, at time-0 banks acknowledge a higher debt capacity of firms and grant more loans. Thanks to this virtuous interplay, a sufficiently forceful intervention from the central bank will enable maximum lending in both countries, $\int_{0}^{Y} B d F(B)$, and all firms with $B \leq Y$ will be able to invest.

By contrast, there exists a $\hat{\gamma}>0$ such that, for all $\gamma>\hat{\gamma},{ }^{17}$ the equilibrium price of asset $P^{*}$ is strictly smaller than $Y$, regardless of the size of liquidity injection. Lending rates reach the zero bound at $L^{*}<L_{\max }$, and liquidity injections beyond $L^{*}$ neither enhance the asset price nor reduce the interest rate. Aggregate lending does not respond,

\footnotetext{
${ }^{16} Y$ is not discounted given that no alternative investment can be undertaken at time-1.

${ }^{17} \bar{\gamma}$ and $\hat{\gamma}$ do not necessarily coincide. For some distribution functions $F(B)$, intermediate levels in $\gamma$ lead to equilibria in which monetary policy has discontinuous effects; see Benmelech and Bergman (2012).
} 
remaining constrained at a sub-optimal level, $\int_{0}^{P^{*}} B d G(B)<\int_{0}^{Y} B d F(B)$. Intuitively, an injection of additional liquidity is ineffective because banks rationally anticipate that lending any incremental fund does not boost collateral values sufficiently to support the additional lending. ${ }^{18}$ The following proposition summarises these results.

Proposition 1 Assume $\delta=0$. In equilibrium:

(i) There is a threshold $\bar{\gamma}>0$ such that, for all $\gamma \leq \bar{\gamma}$, there exists a level $L_{\text {max }}$ at which the asset price satisfies $P^{*}=Y$ and corporate lending is at the maximum level, $\int_{0}^{Y} B d F(B)$.

(ii) There is a threshold $\hat{\gamma}>0$ such that, for $\gamma \geq \hat{\gamma}$, regardless of the liquidity injected, the collateral price does not reach the full value, $P^{*}<Y, \forall L$, and corporate lending will be always strictly lower than $\int_{0}^{Y} B d F(B)$.

(iii) Lending responses to any injection of liquidity coincide across countries, regardless of differences in $\rho_{i}$ and/or $\gamma_{i}$.

Proof See Appendix B.

As discussed above, Proposition 1 shows that, in the benchmark model, monetary policy only encounters the limit highlighted by Benmelech and Bergman (2012). Namely, if the liquidity shock hits a too large share of firms, an excess in the asset supply prevents liquidity injections from increasing debt capacity of firms beyond a sub-optimal level. Nevertheless, monetary policy equally affects both countries; moreover, an integrated market for collateral guarantees an equal transmission of monetary policy even if the magnitude of the liquidity shock hitting firms differs across countries. These results are no longer valid once the model includes the banks' exposure to the sovereign default shock.

\subsection{Full model: sovereign default shock}

In the full model, banks are exposed to a liquidity shock forcing a share of them into bankruptcy if their sovereign defaults at time-1. The introduction of this sovereign-banking nexus generates two mechanisms that crucially impair the transmission of monetary policy.

First, liquidity injected into the risky country's banks will finance the sovereign rather than boosting corporate lending in some circumstances; this implies that, as long as countries differ in sovereign risk, the response of corporate lending to monetary policy diverges across the monetary union countries (Proposition 2). Note that diverging responses result in a framework in which countries neither differ in their real sector nor in their financial system, apart from the difference in sovereign risk which banks are exposed to. Second, sovereign risk in one country can generate negative spillover effects on corporate lending throughout the monetary union via the collateral channel (Proposition 3).

\footnotetext{
${ }^{18}$ This equilibrium is a multi-country version of the 'credit trap' characterised in Benmelech and Bergman (2012).
} 
As for the benchmark, first, I derive the collateral-in-advance constraint that applies in the presence of the sovereign default shock. Then, I characterise the equilibrium on the market for funds with exogenous asset price. Finally, I include an endogenous market for liquidated assets, which makes it possible to analyse the full impact of monetary policy on the interplay between liquidity, collateral value, bank lending, and investment.

\subsubsection{Stochastic collateral-in-advance constraint}

The introduction of the sovereign default shock makes the price of the asset stochastic. For a given level of liquidity injected $L$, if sovereign default realises the price of asset can be lower, say $P_{l}(L)$, than it would be if sovereign default does not realise, say $P_{h}(L) .{ }^{19}$ The asset price determines the time- 1 repayment that firms can commit to, therefore its randomness obviously affects their debt capacity at time- 0 . However, the stochastic version of the collateral-in-advance constraint is very similar to the deterministic one, as the following lemma shows.

Lemma 2 Suppose that, for a given level of liquidity injected $L$, the price of asset at time-1 can be $P_{l}(L)$ with probability $\eta$ and $P_{h}(L)$ with probability $1-\eta$, and define $E(P) \equiv \eta P_{l}(L)+(1-\eta) P_{h}(L)$. Then, the stochastic equivalent of the collateral-in-advance constraint (9) is given by:

$$
b \leq \frac{E(P)}{1+r_{i}^{f}},
$$

where $r_{i}^{f}$ is the country-i equilibrium interest rate on loans obtained by firms with borrowing requirement $B<P_{l}(L)$.

Proof See Appendix B.

The intuition for this result is as follows. All firms with borrowing requirement $B \leq$ $P_{l}(L) /\left(1+r_{i}^{f}\right)$ are not affected by the randomness of the asset price. At time- 0 , their credit demand does not exceed the amount of funds they can commit to repay at time-1, even in the bad state of the world - i.e. the one in which $P=P_{l}(L)$. As a full repayment is guaranteed regardless of differences in their borrowing needs, the equilibrium interest rate on loans with $B \leq P_{l}(L) /\left(1+r_{i}^{f}\right)$ will be the same, and given by $r_{i}^{f}$.

This does not hold for firms whose borrowing requirements exceed $P_{l}(L) /\left(1+r_{i}^{f}\right)$ : these firms cannot commit to repay more than $P_{l}(L)$ at time- 1 if the bad state of the world realises. However, this does not necessarily imply that they will not be able to borrow and invest at time-0. In other words, the relevant collateral-in-advance exceeds $P_{l}(L) /\left(1+r_{i}^{f}\right)$. This is because banks and firms can write state-contingent contracts specifying a lower payment, $P_{l}(L)$, if the bad state of the world realises, and a greater one otherwise. This larger payment must fulfill two conditions. First, it cannot exceed $P_{h}(L)$, the maximum amount that a firm can commit to repay at time-1 if the good state of the world realises. Second, it must compensate for the banks' risk of getting a repayment

\footnotetext{
${ }^{19}$ Proposition 3 states the conditions under which sovereign default implies a lower asset price.
} 
that, if the bad state of the world realises at time-1, will be lower than the funds lent at time-0. Specifically, the expected return on loans exceeding $P_{l}(L) /\left(1+r_{i}^{f}\right)$ must equal the expected return on loans that do not exceed this threshold. This implies that the former loans will entail an interest rate premium compared to the latter.

The proof of Lemma 2 shows that, for any equilibrium interest rate $r_{i}^{f}$, the above conditions are satisfied for firms having borrowing requirement up to $E(P) /\left(1+r_{i}^{f}\right)$, which thus constitutes the relevant collateral-in-advance constraint in the full model.

\subsubsection{Equilibrium for a given asset price}

In the benchmark model, any optimal loan contract guarantees repayment up to the liquidation value of the asset in any future state of the world; conversely, a sovereign does not repay bondholders in the next period with probability $\rho_{i}$. Hence, profit maximisation implies in a straightforward manner that banks underwrite risky sovereign debt only if its yield is greater than the lending rate, and sufficient to equalise the expected return on sovereign bonds to the one on firm loans, i.e. $r_{i}^{g}=\frac{r_{i}+\rho_{i}}{1-\rho_{i}}$.

By contrast, when the sovereign default shock is included, banks make present investment decisions anticipating that, if domestic sovereign default occurs in the next period, a share of them will be forced into bankruptcy. This implies that, conditional on sovereign default occurring, a positive return realizing at time-1 increases banks' expected profits to a minor extent than in the benchmark model. Consequently, the yield threshold at which the expected return on domestic sovereign bonds equals the expected return on firm loans is lower, and equal to $r_{i}^{g}=\frac{r_{i}\left(1-\rho_{i}\right)+\rho_{i}(1-\delta)}{1-\rho_{i}}$.

The introduction of a sovereign-banking nexus also affects firms' profit maximisation problem. Specifically, firms' expected payoff from depositing their wealth reduces given that banks, if bankrupt, would only repay an amount $\alpha\left(1+r_{i}^{d}\right)(I-B)$ at time-2 rather than $\left(1+r_{i}^{d}\right)(I-B)$ at time-1.

Given a lending rate $r_{i}^{f}$ and a deposit rate $r_{i}^{d}$, a country $i$ 's firm with borrowing requirement $B$ will prefer to undertake the project rather than depositing its wealth in the banks if the following condition holds:

$$
\begin{aligned}
& \gamma\left[X_{1}+E(P)-\left(1+r_{i}^{f}\right) B\right]+(1-\gamma)\left[X_{2}+\left(X_{1}-\left(1+r_{i}^{f}\right) B\right) Y E\left(\frac{1}{P}\right)+X_{2}^{\prime}\right] \geq \\
& \gamma\left[\left(1-\delta \rho_{i}\right)\left(1+r_{i}^{d}\right)(I-B)+\delta \rho_{i} \alpha\left(1+r_{i}^{d}\right)(I-B)+E(P)\right]+ \\
& (1-\gamma)\left[\left(1-\delta \rho_{i}\right)\left(1+r_{i}^{d}\right)(I-B) Y E\left(\frac{1}{P}\right)+\delta \rho_{i} \alpha\left(1+r_{i}^{d}\right)(I-B)+X_{2}^{\prime}\right] .
\end{aligned}
$$

Equation (16) represents the firms' IPC in the 'sovereign default shock' scenario. The IPC becomes tighter as firms' borrowing needs increase (see Appendix B, Lemma 3.o); then, it is convenient to represent the value that equation (16) assumes when $B=I$ :

$$
X_{1}\left[\gamma+(1-\gamma) Y E\left(\frac{1}{P}\right)\right]+X_{2}(1-\gamma) \geq I\left(1+r_{i}^{f}\right)\left[\gamma+(1-\gamma) Y E\left(\frac{1}{P}\right)\right] .
$$

This condition defines an interest rate $\bar{r}_{i}^{f}$ such that a firm with maximal borrowing re- 
quirement is indifferent between the two choices. As equation (16) tightens in $B$, if $r_{i}^{f} \leq \bar{r}_{i}^{f}$ then the IPC is satisfied for all firms. Hence, all firms with borrowing requirement lower than or equal to the discounted value of collateral demand funds to invest in the project, while the others deposit their wealth in the banks. This makes possible to determine the total demand and the total supply of funds in a similar manner as in Section 3.1.

The following lemma characterises the equilibrium emerging in the full model for an exogenous asset liquidation value $P$, and a liquidity injection $L$.

Lemma 3 Assume $\delta>0$. Moreover, assume $\rho_{R}>\rho_{S} \geq 0$, and $\frac{\delta \rho_{R}}{1-\delta \rho_{R}}<\bar{r}_{i}^{f}$. Given an exogenous asset value $P$, in equilibrium:

(i) There is a threshold $\hat{L}$ such that, for any $L \geq \hat{L}$, the firm's investment participation constraint (16) is not biding, $\forall B$. Firms with borrowing requirement satisfying $B \leq$ $\frac{P}{1+r_{i}}$ borrow and undertake the project, the others deposit their wealth.

(ii) There is a threshold $\underline{L}>\hat{L}$ such that, for any $L \leq \underline{L}$, in equilibrium $r_{S}=r_{R}$, and a higher $L$ reduces the interest rate.

(iii) There is a non-empty interval $[\underline{L}, \bar{L}]$ such that: (a) for any $L \in[\underline{L}, \bar{L}]$, country $R$ 's lending rate $r_{R}$ is constant in $L$ and equal to $\frac{\delta \rho_{R}}{1-\delta \rho_{R}}$; (b) at least for some $L \in[\underline{L}, \bar{L}]$, country $S$ ' lending rate $r_{S}$ is reducing in $L$. Then, for any $L>\underline{L}$, in equilibrium $r_{S}<r_{R}$ unless $r_{R}=0$.

(iv) The value of $\underline{L}$ reduces both in the sovereign risk $\rho_{R}$ and in the share of domestic banks exposed to sovereign risk $\delta$. Moreover, if $c$ is sufficiently large, $\bar{L}-\underline{L}$ equals $G_{R}$, the amount of risky country's sovereign debt issued.

Proof See Appendix B.

The intuition behind the results summarised in Lemma 3 is as follows. ${ }^{20}$ The sovereignbanking nexus leads banks to overestimate the expected return on domestic sovereign debt relative to firm loans. This feature has no effect with sufficiently low liquidity, and the monetary transmission mechanism works as in the benchmark model. Nevertheless, once the lending rate equals $\frac{\delta \rho_{i}}{1-\delta \rho_{i}}$, domestic banks perceive equal expected return on sovereign bonds and firm loans. As long as foreign investors hold a positive amount of sovereign debt, the yield is determined by the default risk and cannot reduce. Then, when further liquidity is injected, the availability of high yield bonds prevents domestic banks from reducing lending rates. The collateral constraint does not relax, preventing corporate lending from increasing; the whole liquidity injected is used by banks to underwrite domestic sovereign debt. This 'credit trap' ends only once the entire supply of sovereign debt is in the hands of domestic banks. Beyond this level, liquidity injections simultaneously reduce sovereign yield and lending rates, regaining effectiveness.

\footnotetext{
${ }^{20}$ The assumption that $\frac{\delta \rho_{R}}{1-\delta \rho_{R}}<\bar{r}_{i}^{f}$ simply rules out the trivial case in which sovereign yields are so high that there is no real investment in equilibrium.
} 

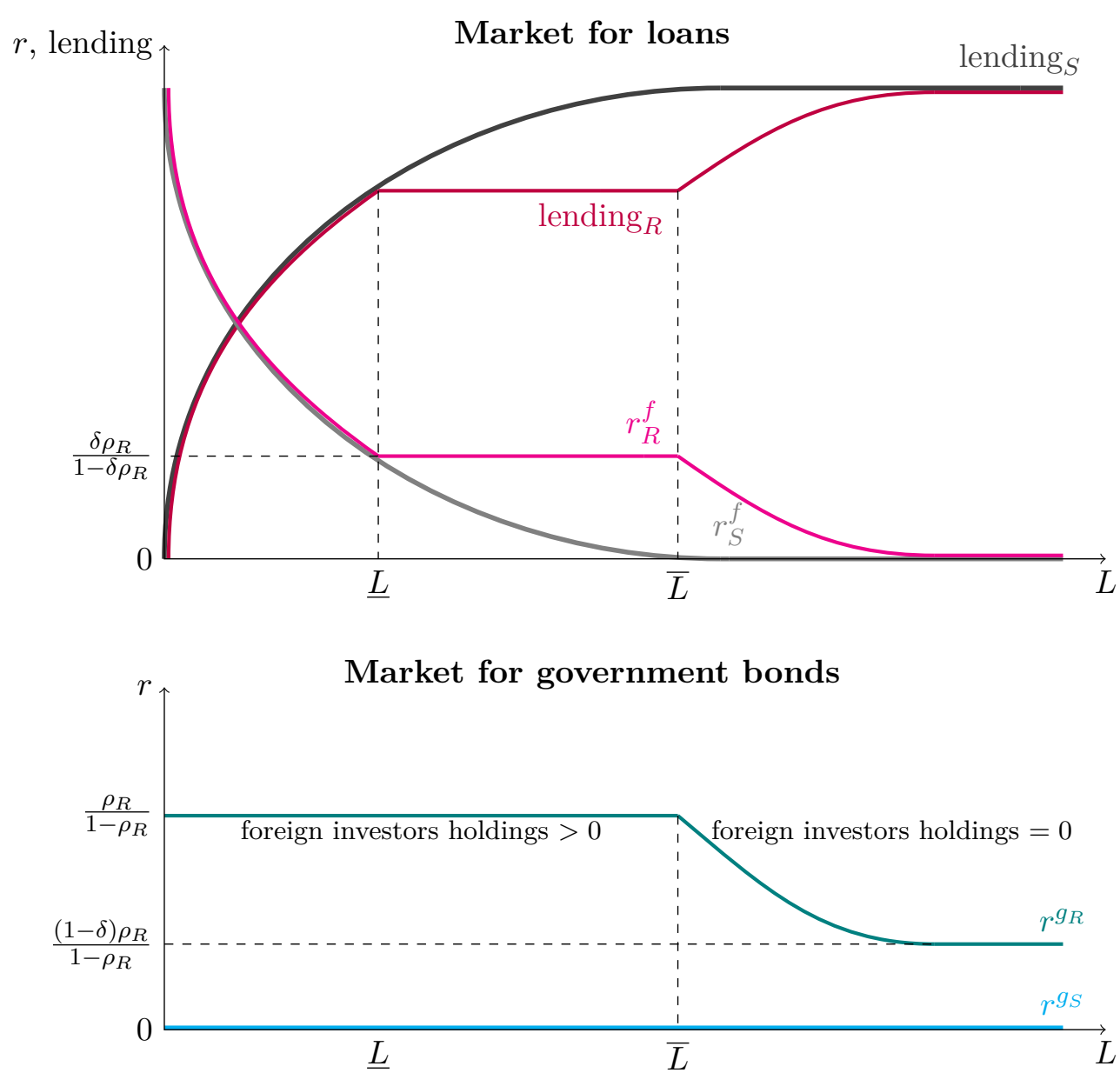

Figure 3: Equilibrium Responses to Liquidity Injections

The figure describes the equilibria on the markets for loans and government bonds as function of the total liquidity injected by the central bank. The price of collateral is considered exogenous; the probability of sovereign default is null in country $S\left(\rho_{S}=0\right)$ and positive in country $R\left(\rho_{R}>0\right)$.

Figure 3 analyzes the case in which the monetary union is composed of a risky country and a safe one. In the safe country, the lending rate continuously decreases as liquidity is injected by the central bank, with monetary policy successfully boosting lending.

By contrast, beyond the threshold $\underline{L}$, the lending rate in country $R$ does not reduce, given that banks can underwrite domestic sovereign debt - which they perceive as granting the same expected return as collateralised firm loans. As long as sovereign debt is available, the lending rate does not reduce, debt capacity of firms does not expand, and banks invest the whole liquidity injected in sovereign bonds. Monetary policy will further stimulate lending in country $R$ only if the liquidity injection is so forceful to let domestic banks hold the entire supply of sovereign debt.

Further noticeable implications include the following. First, a higher sovereign risk increases $\frac{\delta \rho_{R}}{1-\delta \rho_{R}}$ and lowers $\underline{L}$, implying a smaller initial range of liquidity in which monetary policy is effective, and a credit trap equilibrium with lower aggregate lending. The flat section of the curve representing country $R$ 's lending rate in Figure 3 shifts towards the top left. Intuitively, a riskier sovereign debt is traded at a higher yield on the international 
market, but domestic banks perceive it as granting a higher return.

Second, the greater the amount of risky sovereign debt issued, the greater the liquidity range in which monetary policy is not effective, $\bar{L}-\underline{L}$. This is due to the fact that domestic banks absorb the whole supply of sovereign debt at a higher liquidity level $\bar{L}$. In Figure 3 , the flat section of the curve representing country $R$ 's lending rate expands.

Third, the greater $\delta$ - the share of banks exposed to the sovereign default shock - the less banks internalise sovereign risk; hence, the greater $\frac{\delta \rho_{R}}{1-\delta \rho_{R}}$ and the smaller $\underline{L}$. Hence, the initial range of liquidity in which monetary policy is effective is smaller, and the credit trap is characterised by a lower investment. The flat section of the curve representing country $R$ 's lending rate in Figure 3 shifts towards the top left.

In the rest of this section, I show how collateral price dynamics, first, affect the results described in Lemma 3 and second, lead sovereign risk to generate spillover effects also in the safe country.

\subsubsection{Equilibrium with endogenous asset price: asymmetric lending responses}

As underlined in the benchmark model, liquidity injections do not only affect lending through a reduction in the interest rate. As the project grants higher returns than bank deposits, a higher aggregate investment boosts the total wealth available to firms demanding assets in the next period. This, in turn, can boost its liquidation price. At time- 0 , banks upgrade their expectations of the collateral value, acknowledge a higher debt capacity of firms, and hence grant more loans.

This affects the results in Lemma 3: although liquidity is in the region where country $R$ 's lending rate cannot reduce, a higher lending in country $S$ can boost asset prices. This way, constant its denominator, the collateral-in-advance constraint in country $R$ can still relax hanks to a higher value of its numerator.

These collateral price dynamics possibly reduce the extent to which lending remains constrained in the risky country, but have second-order effects only, without preventing asymmetric responses across countries. Results are described in the following proposition.

Proposition 2 Assume $\delta>0$. If sovereign default risks differ, $\rho_{R}>\rho_{S} \geq 0$, corporate lending responds differently to liquidity injections across the monetary union countries. In particular, there is an interval $\left[L^{\prime}, L^{\prime \prime}\right]$ such that, for $L \in\left[L^{\prime}, L^{\prime \prime}\right]$ :

(i) In country $S$, the lending rate reduces as $L$ increases, and banks lend the whole liquidity injected to domestic firms;

(ii) In country $R$, the lending rate does not reduce and remains constant at $\frac{\delta \rho_{R}}{1-\delta \rho_{R}}$ as $L$ increases, and banks - mainly - use the liquidity injected to underwrite domestic sovereign debt;

(iii) In country $R$, corporate lending will increase only to the extent that a higher lending in country $S$ boosts the expected price of assets, so relaxing the collateral constraint. 
(iii) The greater the $\delta$ and/or the $\rho_{R}$, the lower the threshold $L^{\prime}$; the length of the interval $\left[L^{\prime}, L^{\prime \prime}\right]$ is non-decreasing in country $R$ 's sovereign debt supply, and strictly increasing if $c$ is sufficiently large.

Proof See Appendix B.

Discussion Proposition 2 describes a mechanism through which sovereign risk generates asymmetric lending responses in a monetary union. The interpretation of the results closely follow Lemma 3. In the safe country, an increase in the aggregate liquidity produces both a reduction in the lending rate and possibly an increase in the expected value of collateral. Debt capacity of firms expands and banks lend the whole liquidity injected by the central bank to domestic firms, until the lending rate reaches the lower bound. ${ }^{21}$

In the risky country, instead, the transmission of monetary policy to corporate lending is impaired. As exposed to the sovereign default shock, banks underestimate the return on firm loans relative to the one on domestic sovereign bonds. Beyond a certain level of liquidity injected, and as long as banks have the opportunity to underwrite additional sovereign debt, the lending rate does no longer respond to monetary policy. Given the presence of a collateral constraint, this feature implies that the debt capacity of domestic firms will not react to liquidity injections, unless a higher lending in country $S$ is able to raise the expected price of collateral.

In the model, a greater share of banks exposed to the sovereign default shock and/or a higher sovereign risk reduce the initial range of liquidity in which monetary policy is fully effective, as well as implying a credit trap equilibrium with lower aggregate lending. Furthermore, a greater supply of risky sovereign debt enlarges the range of liquidity within which this credit trap realises. Consequently, a higher level in each of these dimensions will imply an exacerbated asymmetry in lending responses to monetary policy across countries.

Proposition 2 is derived under the simplifying assumption that firms can deposit their initial wealth in domestic banks only. Suppose we relax this assumption: as country $R$ 's banks are more likely than country $S$ ' ones not to repay depositors at time-1, their deposits should grant a sufficiently higher interest rate to prevent domestic firms from moving their wealth in foreign banks. It would follow an even higher lending rate in country $R$, to reflect the higher bank funding cost. Suppose instead that, in equilibrium, firms' wealth is unevenly distributed across countries - i.e. with a fraction, or the total, of private deposits moving from the riskier banking system to the safer one. Although safe country's banks can lend funds to firms in the risky country, the presence of a cost on foreign lending will still imply either a higher equilibrium lending rate and/or a lower volume of lending in country $R$. Therefore, by relaxing this assumption, lending responses to liquidity injections will still diverge, possibly showing even more extreme patterns as those described in Proposition 2.

These predictions are consistent with the evidence presented in the Introduction and with periphery banks being the largest borrowers of funds from the two 3-year LTROs

\footnotetext{
${ }^{21}$ This lower bound is zero if $\rho_{S}=0$ and larger than zero otherwise, but strictly lower than $\frac{\delta \rho_{R}}{1-\delta \rho_{R}}$.
} 
in 2011-12 22 - funds they mainly used to underwrite domestic sovereign debt. Furthermore, in spite of the ECB's accommodative monetary policy during the crisis, lending rates in the periphery remained high and tracked domestic sovereign yields instead of the policy rate $^{23}$ - in line with the mechanism that the model displays. On the other hand, as the ECB's intervention intensified during the years 2014-15, sovereign spreads reduced and were followed by a compression in lending rates in the periphery (Figure 5 in the Appendix). This is consistent with the model prediction that, with sufficiently high liquidity injections, monetary policy regains effectiveness in reducing both sovereign yields and lending rates in stressed countries.

\subsubsection{Equilibrium with endogenous asset price: spillover effects of sovereign risk}

In this section I show that, when banks are exposed to the sovereign default shock, sovereign risk can generate negative spillover effects on lending in the safe country of the monetary union through the collateral channel.

The demand for and the supply of liquidated assets are determined in a similar manner as in Section 3.1.2. However, differently than in the benchmark model, the total time1 wealth available to firms demanding liquidated assets depends on the realisation of sovereign default. Conditional on sovereign default not realizing, the expected time-1 wealth of firms demanding asset equals:

$$
Q(\underline{B}, \underline{r})=\sum_{i}\left(1-\gamma_{i}\right)\left[\int_{0}^{\frac{E_{i}(P)}{1+r_{i}}}\left(X_{1}-B\left(1+r_{i}\right)\right) d F(B)+\int_{\frac{E_{i}(P)}{1+r_{i}}}^{I}(I-B)\left(1+r_{i}\right) d F(B)\right],
$$

where terms can be interpreted similarly as in Section 3.1.2. ${ }^{24}$

By contrast, if at time- 1 sovereign default occurs in country $i$, this would force a share $\delta$ of domestic banks into bankruptcy. These banks would only repay to creditor firms an amount $\alpha\left(1+r_{i}\right)(I-B)$ at time-2 instead of $\left(1+r_{i}\right)(I-B)$ at time- 1 . These firms are potential buyers of the asset liquidated at time-1. Hence, conditional on sovereign default realizing in country $i$, the expected time- 1 wealth available to the domestic demand for liquidated assets reduces by an amount equal to:

$$
\delta \int_{\frac{E_{i}(P)}{1+r_{i}}}^{I}(I-B)\left(1+r_{i}\right) d F(B) .
$$

To consider how this feature affects the transmission of monetary policy to corporate lending, it is convenient to compare the asset market equilibrium in the full model with

\footnotetext{
${ }^{22}$ See also TARGET2 balances, which show a substantial flow of central bank liquidity from the core to the periphery during the crisis (Fagan and McNelis 2014).

${ }^{23}$ From June 2010 to March 2015, the correlation between domestic sovereign yields and NFCs lending rates exceeded the one between the latter and the MRO by $43.7 \%$ in Italy and by $19.2 \%$ in Spain. On the other hand, the correlation between the MRO and lending rates was higher than the one between the latter and domestic sovereign yields by $4.4 \%$ in France and by $9.8 \%$ in Germany.

${ }^{24}$ Note that outcomes realizing in the future state of the world where sovereign default occurs enter the expected profit of domestic banks to a degree $1-\delta<1$ only. This implies that, differently than in the benchmark model, if $\rho_{i} \neq \rho_{j}$ then $E_{i}(P) \neq E_{j}(P)$.
} 
the one that would emerge in the benchmark model.

Suppose that the liquidity shock hitting firms has a magnitude $\gamma<\hat{\gamma}$. From Proposition 1, we know that in the benchmark model economy sufficiently forceful liquidity injections will allow the asset price to reach its full value, $Y$, and corporate lending to reach its maximum level in both countries, $\int_{0}^{Y} B d F(B)$.

By contrast, in the full model the occurrence of sovereign default would reduce the time-1 liquidity available to firms demanding liquidated assets. In that future state of the world, a similar reduction in liquidity can imply that the liquidation price of assets will be strictly lower than the full value, regardless of the monetary policy stance. Specifically, there are values of $\gamma<\hat{\gamma}$ such that, if sovereign default does not occurr, the time-1 equilibrium price of asset will be given by:

$$
\mathbf{P}\left(\underline{B}, \underline{r}, \operatorname{sdef}_{i}=0\right)=\min \left(\frac{Q\left(\underline{B}, \underline{r}, \operatorname{sdef}_{i}=0\right)}{\gamma_{R}+\gamma_{S}}, Y\right)=Y,
$$

but, if sovereign default occurs, we have instead that:

$$
\mathbf{P}\left(\underline{B}, \underline{r}, \operatorname{sdef}_{i}=1\right)=\min \left(\frac{Q\left(\underline{B}, \underline{r}, \operatorname{sdef}_{i}=1\right)}{\gamma_{R}+\gamma_{S}}, Y\right)<Y .
$$

When banks make their investment decisions at time-0, they take into account that, with probability $\rho_{i}$, the liquidation price of collateral will be lower than $Y$, adjusting downward their expectations of the price of collateral and debt capacity of firms. Therefore, the collateral constraint becomes binding for a larger share of firms, and corporate lending reduces. Intuitively, a lower collateral price implies that firms' capacity to repay loans in the next period is reduced; hence, banks reduce the maximum amount of funds that they are willing to grant in a loan contract. ${ }^{25}$ Spillover effects of sovereign risk are characterised in the following proposition.

Proposition 3 Assume $\delta>0$. If sovereign default risk $\rho_{i}>0$ for some $i$, then:

(i) There is a threshold $\hat{\gamma}_{\delta}>0$ such that, for $\gamma \geq \hat{\gamma}_{\delta}$, for any L, the expected price of collateral is strictly smaller than $Y$, and at time- 0 country $j$ 's corporate lending is constrained at a level strictly lower than $\int_{0}^{Y} B d F(B)$.

(ii) This threshold satisfies $\hat{\gamma}_{\delta}<\hat{\gamma}$, i.e. the range of the liquidity shock values within which, regardless of $L$, lending remains constrained at a sub-optimal level is greater than in the benchmark model.

(iii) An increase in $\delta$ and/or $\rho_{i}$ strengthens spillover effects of sovereign risk. Specifically, a greater $\delta$ reduces $\hat{\gamma}_{\delta}$, i.e. it increases the range of values within which credit traps emerge; a greater $\rho_{i}$ implies a lower aggregate investment in a credit trap equilibrium.

Proof See Appendix B.

\footnotetext{
${ }^{25}$ Note that country $i$ 's sovereign risk depresses collateral values to a greater extent in country $j$ than in country $i$. This is because the asset price will be lower exactly if country $i$ 's sovereign defaults: but in this case a share $\delta$ of domestic banks will be bankrupt. Hence, at time- 0 , this potential reduction in the value of collateral enters the expected profits of country $i$ 's banks to a degree $1-\delta<1$.
} 
Discussion Proposition 3 underlines a transmission channel able to explain weak credit dynamics throughout the monetary union. By depressing collateral values, sovereign risk can generate negative cross-border effects that persist regardless of the strength of the central bank intervention under some circumstances - namely, if the impact of the crisis on corporate liquidity, captured by the parameter $\gamma$, is sufficiently severe.

Intuitively, even in a country that does not suffer from sovereign risk, banks rationally anticipate that the possible occurrence of sovereign default in the other country is likely to cause, through disruptions in the banking system, liquidity problems for firms operating there, so reducing their demand for liquidated assets. With a sufficiently integrated asset market, a fall in demand from one country will depress the asset price in the other. But lower collateral values imply a lower ability to repay debt in the next period: hence, banks grant less funds in loan contracts. Consequently, aggregate lending reduces even in the country that is not directly affected by sovereign risk. Finally, Proposition 3 also shows that a greater share of banks exposed to the sovereign default shock, as well as a higher sovereign risk in country $R$, will exacerbate the risk of contagion across economies.

Banks, as intermediaries in channeling the liquidity injected to borrowers, play a crucial role for the emergence of credit traps. This implies that measures able to boost corporate liquidity and/or asset prices beyond the banking intermediation channel would overcome the limitations underlined above, mitigating both the impaired transmission of the monetary stimulus to the stressed country and the spillover effects of sovereign risk.

Proposition 3 is derived under the simplifying assumption of one market for collateral in the monetary union, but is robust to the introduction of cross-country segmentation in such market. Indeed, to obtain results qualitatively equivalent to those stated in Proposition 3 , it is sufficient that markets are sufficiently integrated to let the asset price in country $i$ being affected by a drop in the demand for asset in country $j$.

The mechanism shown in Proposition 3 has the following testable implications. In industries with integrated collateral markets across the monetary union countries, asset prices and debt capacity of firms are more likely to respond to an expected reduction in the asset demand due to sovereign risk in another country. By contrast, industries with segmented collateral markets are more likely to be immune to this risk.

The following empirical strategy could allow to test this hypothesis. Consider a panel data set of secured debt tranches of an industrial sector in a core country of the euro area at two different time periods, before and after the emergence of high sovereign yield spreads. Debt tranches whose underlying collateral markets exhibit larger degree of integration with the euro area periphery (e.g., measured by the volume of cross-border trading) should display larger price declines (or lower price increases) than tranches whose underlying collateral markets are less integrated. ${ }^{26}$ Should the data support this hypothesis, contrasting sovereign market turmoil - and/or weakening the link between a country's

\footnotetext{
${ }^{26}$ Similarly, one could test the prediction that a higher investment in the core, by raising collateral values, can relax the credit trap in stressed countries (Proposition 2.iii). In this case, data would show that secured debt in the periphery whose underlying collateral market is more integrated with the core should display lower price declines than debt tranches with less integrated collateral market.
} 
banking and the health of its public finances - would be beneficial for the transmission of the ECB's monetary policy even to economies that do not directly suffer from high sovereign risk. Such study is beyond the scope of this paper and left for future research.

\section{Conclusion}

This paper studies the limitations of non-standard monetary policy in stimulating lending in a monetary union suffering from disruptions in the financial system and a sovereign debt crisis. The framework includes the hypothesis that banks are exposed to a liquidity shock if their sovereign defaults, and studies how this feature affects the transmission of monetary policy to corporate lending.

The model shows that a similar sovereign-banking nexus can crucially impair a proper monetary transmission mechanism. The theoretical mechanisms provide a clear interpretation of the heterogeneous transmission of the ECB's policy measures to the economies of the euro area, suggesting that in times of high sovereign yields liquidity injections can lead banks in stressed countries to increase their domestic sovereign holdings, rather than channeling funds to the real economy. Furthermore, the model highlights a new transmission channel, with testable implications, through which sovereign risk in one country can constrain corporate lending throughout the monetary union.

The results of the analysis suggest that structural reforms of the financial system could be beneficial, if able to weaken the link between a country's banking and the health of its public finances. Moreover, intervention in policy areas other than monetary policy as fiscal policy - could more strongly stimulate investment, by circumventing a banking system overwhelmed by sovereign exposure.

A limit of the present analysis is that it abstracts from strategic default considerations. It can be interesting to augment the framework so as to model governments who maximise domestic welfare, and face preexisting sovereign debt that can be financed by taxing domestic firms, by issuing new sovereign debt, or can be defaulted. A similar extension would make it possible to study how the monetary policy stance, set at the monetary union level, might affect the cost of raising sovereign debt, hence governments' fiscal policy and strategic default decisions taken at the national level.

\section{References}

Acharya, Viral V., Tim Eisert, Christian Eufinger, and Christian W. Hirsch (2015), "Real Effects of the Sovereign Debt Crisis in Europe: Evidence from Syndicated Loans", Working Paper.

Acharya, Viral V., and Sascha Steffen (2015), "The Greatest Carry Trade Ever? Understanding Eurozone Bank Risks", Journal of Financial Economics, 115 (2): 215-236.

Adelino, Manuel, Antoinette Schoar, and Felipe Severino (2015), "House Prices, Collateral, and Self-Employment," Journal of Financial Economics, 117(2): 288-306.

Altavilla, Carlo, Marco Pagano, and Saverio Simonelli (2016), "Bank Exposures and Sovereign Stress Transmission," ECB Working Paper No. 1969. 
Ari, Anil (2016), "Sovereign Risk and Bank Risk-Taking," Working Paper.

Battistini, Niccolò, Marco Pagano, and Saverio Simonelli (2014), "Systemic Risk, Sovereign Yields and Bank Exposures in the Euro Crisis," Economic Policy, 29(78): 203-251.

Bebchuk, Lucian A., and Itay Goldstein (2011), "Self-fulfilling Credit Market Freezes," Review of Financial Studies, 24(11): 3519-3555.

Benmelech, Efraim, and Nittai K. Bergman (2011), "Bankruptcy and the Collateral Channel," Journal of Finance, 66(2): 337-378.

(2012), "Credit Traps," American Economic Review, 102(6): 3004-3032.

Bernanke, Ben, and Mark Gertler (1989), "Agency Costs, Net Worth, and Business Fluctuations," American Economic Review, 79(1): 14-31.

Bernanke, Ben, Mark Gertler, and Simon Gilchrist (1996), "The Financial Accelerator and the Flight to Quality," Review of Economics and Statistics, 78(1): 1-15.

- (1999), "The Financial Accelerator in a Quantitative Business Cycle Framework," Handbook of Macroeconomics, by John B. Taylor and Michael Woodford, Elsevier, 1(21): 1341-93.

Bocola, Luigi (2016), "The Pass-Through of Sovereign Risk," Journal of Political Economy, 124(4): $879-927$.

Broner, Fernando, Aitor Erce, Alberto Martin, and Jaume Ventura (2014), "Sovereign Debt Markets in Turbolent Times: Creditor Discrimination and Crowding-Out Effects," Journal of Monetary Economics, 61(1): 114-142.

Brunnermeier, Markus K., Luis Garicano, Philip R. Lane, Marco Pagano, Ricardo Reis, Tano Santos, Stijn Van Nieuwerburgh, and Dimitri Vayanos (2016), "The Sovereign-Bank Diabolic Loop and ESBies," American Economic Association Papers and Proceedings, 106(5): 508-512.

Buera, Francisco, and Juan P. Nicolini (2014), "Liquidity Traps and Monetary Policy: Managing a Credit Crunch," Working Paper 714, Federal Reserve Bank of Minneapolis.

Crosignani, Matteo (2015), "Why are Banks not Recapitalized during Crises?," ONB Working Paper No. 203.

Crosignani, Matteo, Miguel Faria-e-Castro, and Luis Fonseca (2017), "The (Unintended?) Consequences of the Largest Liquidity Injection Ever," Finance and Economics Discussion Series 2017011, Washington: Board of Governors of the Federal Reserve System.

De Marco, Filippo (2014), "Bank Lending and the Sovereign Debt Crisis," Boston College Working Paper.

Fagan, Gabriel and Paul D. McNelis (2014), "TARGET Balances and Macroeconomic Adjustment to Sudden Stops in the Euro Area," IIIS Discussion Paper No. 465.

Fahr, Stephan, Roberto Motto, Massimo Rostagno, Frank Smets, and Oreste Tristani (2011), "Lessons for Monetary Policy Strategies from the Recent Past," Approaches to Monetary Policy Revisited: Lessons from the Crisis, Jarocinski, Smets and Thimann ed., ECB, 26-66.

Farhi, Emmanuel, and Jean Tirole (forthcoming), "Deadly Embrace: Sovereign and Financial Balance Sheets Doom Loops," Review of Economic Studies.

Gennaioli, Nicola, Alberto Martin, and Stefano Rossi (2014), "Sovereign Default, Domestic Banks, and Financial Institutions," Journal of Finance, 69(2): 819-866.

Gorton, Gary, and Guillermo Ordoñez (2014), "Collateral Crises," American Economic Review, 104(2): 343-378.

Hart, Oliver, and John Moore (1994), "A Theory of Debt Based on the Inalienability of Human Capital," Quarterly Journal of Economics, 109(4): 841-79.

(1998), "Default and Renegotiation: A Dynamic Model of Debt," Quarterly Journal of Economics, 113(1): 1-41. 
Hertzel, Michael G., and Micah S. Officer (2012), "Industry Contagion in Loan Spreads," Journal of Financial Economics, 103(3): 493-506.

Kiyotaki, Nobuhiro, and John Moore (1997), "Credit Cycles," Journal of Political Economy, 105(2): $211-48$.

Lane, Philip R. (2012), "The European Sovereign Debt Crisis," Journal of Economic Perspectives, 26(3): 49-68.

Mishkin, Frederic (2011), "Monetary Policy Strategy: Lessons from the Crisis", Approaches to Monetary Policy Revisited: Lessons from the Crisis, Jarocinski, Smets and Thimann ed., ECB, $67-118$.

Ongena, Steven, Alexander Popov, and Neeltje van Horen (2016), "The Invisible Hand of the Government: Moral Suasion during the European Sovereign Debt Crisis," ECB Working Paper No. 1937.

Ortiz-Molina, Hernan, and Gordon M. Phillips (2014), "Real Asset Illiquidity and the Cost of Capital," Journal of Financial and Quantitative Analysis, 49(1): 1-32.

Perri, Fabrizio, and Vincenzo Quadrini (2011), "International Recessions," NBER Working Paper 17201.

Popov, Alexander, and Neeltje van Horen (2015), "Exporting Sovereign Stress: Evidence from Syndicated Bank Lending during the Euro Area Sovereign Debt Crisis," Review of Finance, 19(5): $1825-1866$.

Shleifer, Andrei, and Robert W. Vishny (1992), "Liquidation Values and Debt Capacity: A Market Equilibrium Approach," Journal of Finance, 47(4): 1343-66.

(2010), "Unstable Banking," Journal of Financial Economics, 97: 306-318.

(2011), "Fire Sales in Finance and Macroeconomics," Journal of Economic Perspectives, 25(1): 29-48.

Standard \& Poor's (2004), "Sovereign Risk for Financial Institutions," RatingsDirect on the Global Credit Portal.

Credit Portal.

(2011), "Banks: Rating Methodology and Assumptions," RatingsDirect on the Global

Uhlig, Harald (2014), "Sovereign Default Risk and Banks in a Monetary Union," German Economic Review, 15(1): 23-41.

van der Kwaak, Christiaan (2017), "Financial Fragility and Unconventional Central Bank Lending Operations," SOM Research Reports No. 17005-EEF, University of Groningen. 


\section{Appendix A. Firms' maximisation problem}

Regardless of the bank's exposure to domestic sovereign default risk, the firms' expected payoff from undertaking the project is given by:

$$
\begin{array}{r}
E\left(V_{P}\right)=\gamma_{i}\left[\mathbf{1}_{I} X_{1}+E(P)-\left(1+r_{i}^{f}\right) b\right]+\left(1-\gamma_{i}\right)\left[\mathbf{1}_{I} X_{2}+y\left(\mathbf{1}_{I} X_{1}-\left(1+r_{i}^{f}\right) b\right)\right. \\
\left.+(1-y)\left(\mathbf{1}_{I} X_{1}-\left(1+r_{i}^{f}\right) b\right) Y E\left(\frac{1}{P}\right)+X_{2}^{\prime}\right]
\end{array}
$$

where $\mathbf{1}_{I}$ is an indicator function assuming value 1 if the firm obtains sufficient funds to invest in the project, $b+A \geq I$, and 0 otherwise. With probability $\gamma_{i}$, at time- 1 the firm is hit by a liquidity shock, forced to liquidate assets and consume its wealth, constituted by the return on project, $X_{1}$, plus the expected liquidation value of the asset, $E(P)$, minus the bank loan repayment, $\left(1+r_{i}^{f}\right) b$. With probability $1-\gamma_{i}$, the firm can continue its business until time-2, when the project generates $X_{2}$ and the asset generates $X_{2}^{\prime}$. In this case, the firm can allocate a share $1-y$, with $y \in[0,1]$, of its time-1 wealth to asset purchases, with expected price $E(P)$ and time-2 return $Y$.

By contrast, the probability $\delta \rho_{i}$ of bank bankruptcy affects returns on deposits, given that in this case banks only repay $\alpha\left(1+r_{i}^{d}\right) A$ at time-2, with $\alpha \in(0,1]$, rather than $\left(1+r_{i}^{d}\right) A$ at time- 1 .

Firms' expected payoff, therefore, will be given by:

$$
\begin{array}{r}
E\left(V_{N P}\right)=\gamma_{i}\left[\left(1-\delta \rho_{i}\right)\left(1+r_{i}^{d}\right) A+\delta \rho_{i} \alpha\left(1+r_{i}^{d}\right) A+E(P)\right] \\
+\left(1-\gamma_{i}\right)\left\{\left(1-\delta \rho_{i}\right)\left[y\left(1+r_{i}^{d}\right)+(1-y)\left(1+r_{i}^{d}\right) Y E\left(\frac{1}{P}\right)\right] A+\delta \rho_{i} \alpha\left(1+r_{i}^{d}\right) A+X_{2}^{\prime}\right\} .
\end{array}
$$

Financial frictions require that the financial contract is incentive compatible, and this can limit the firm's ability to obtain funds from banks and hence to undertake the project. Define $\Xi$ as a financial contract - a three-dimensional vector specifying: (i) time-0 debt, $b$, (ii) time-1 repayment, and (iii) penalty in case of no repayment - and $\boldsymbol{\Xi}$ as the set of optimal financial contracts (which is characterised in Section 3.1.1). The financial friction constrains the amount of obtainable funds $b$ to be an element of an optimal financial contract, $b: \Xi \in \mathbf{\Xi}$.

Therefore, the maximisation problem of a firm whose wealth is $A$ is given by:

$$
\begin{aligned}
\max _{\xi \in\{0,1\}, b, y \in[0,1]} & \xi E\left(V_{P}\right)+(1-\xi) E\left(V_{N P}\right) \\
\text { s.t. } & \left\{\begin{array}{cc}
b: \Xi \in \Xi, & \text { if } \xi=1 \\
b=0, & \text { otherwise }
\end{array}\right.
\end{aligned}
$$

Note that: (i) as the lending rate is greater or equal than the deposit rate in any equilibrium, firms borrow only if they undertake the project, then $b=\{0, B\}$, and (ii) as the asset price satisfies $P \leq Y$ in any equilibrium, firms allocate their whole time-1 wealth in asset purchases, i.e. $y^{*}=0$. If one takes these two conditions and the collateral-in-advance constraint into account, the payoff in equation (1) in the Setup is equivalent to equation (18) above. 


\section{Appendix B. Proofs}

\section{Proof of Lemma 1}

(i) First, as international investors are willing to underwrite country $i$ 's sovereign bonds at an interest rate $r_{I N T}^{g_{i}}=\frac{\rho_{i}}{1-\rho_{i}}$, their equilibrium interest rate $r_{i}^{g}$ cannot exceed $\frac{\rho_{i}}{1-\rho_{i}}, \forall i$; at the same time, $r_{i}^{g}$ cannot be lower than $\frac{\rho_{i}}{1-\rho_{i}}, \forall i$, otherwise underwriting sovereign debt would lead to expected losses; then, in equilibrium it must be $r_{i}^{g}=\frac{\rho_{i}}{1-\rho_{i}}, \forall i$. Second, all banks, regardless of the country where they are based, are indifferent between lending funds to firms at an interest rate $r_{i}$ and underwriting country $i$ 's sovereign bonds, $\forall i,{ }^{27}$ if and only if the expected returns on the two investments are equal, $1+r_{i}=\left(1-\rho_{i}\right)\left(1+r_{i}^{g}\right) \Leftrightarrow r_{i}^{g}=\frac{r_{i}+\rho_{i}}{1-\rho_{i}}{ }^{28}$ However, as $r_{i}^{g} \leq \frac{\rho_{i}}{1-\rho_{i}}, \forall i$, for any $r_{i}>0$, firm loans guarantee a higher expected return than government bonds, and banks supply funds to firms only (provided that the collateral-in-advance constraint is satisfied in any loan contract). It results that, for any $r_{i}>0$, the overall supply of funds from banks and the overall effective demand from firms must equal. Only if $r_{i}=0$, government bonds, from both countries, and firm loans grant the same (null) expected returns. In this case, banks are indifferent between the following choices: lending funds to firms at a zero interest rate, up to the limit fixed by the collateral-in-advance constraint in any loan contract; depositing funds in the central bank; underwriting country $i$ 's sovereign debt that grants yield $\frac{\rho_{i}}{1-\rho_{i}}$; or holding a differentiated sovereign bonds portfolio with any weight $\in[0,1]$.

(ii.a) In the following, I prove that in equilibrium country $i$ 's banks do not lend funds to country $j$ 's firms, $\forall i, j$. From (i), we know that country $i$ 's banks underwrite a positive amount sovereign debt only if $r_{i}=0, \forall i$. Then, for any aggregate liquidity $L<L_{\max }$ - where $L_{\max }$ is the level for which $r_{i}=0$ - the whole supply of funds is invested in firm loans only. Assume the aggregate liquidity is any $L<L_{\max }$, and the two markets for funds are in equilibrium for $r_{i}>r_{j}$. If $r_{j}$ is the country $j$ 's equilibrium interest rate on domestic loans, the presence on a marginal cost on foreign lending and a no arbitrage condition imply that the equilibrium lending rate to foreign firms will be $r_{j}+c$. Firstly, consider the case where $r_{i}>r_{j}+c$. Firms in country $i$ with $B \leq \frac{P}{1+r_{j}+c}$, and whose IPC is satisfied, apply for foreign loans; the others deposit wealth in domestic banks. But then, country $i$ 's aggregate supply of funds will be greater or equal to $L+\int_{P /\left(1+r_{i}\right)}^{I}(I-B) d F(B)>0$. As neither domestic nor foreign firms demand those funds, $r_{i}$ must move down. Then, in equilibrium it must be $r_{i} \leq r_{j}+c$, at which no firm prefer to apply for foreign loans. ${ }^{29}$ Then, there is no equilibrium where $r_{i}>r_{j}+c$; this implies that banks never lend funds to firms abroad in equilibrium.

(ii.b) In the following, I prove that $r_{R}=r_{S}=r, \forall L$. From (ii.a) we know that, in equilibrium, it is not possible that $r_{i}>r_{j}+c$; it is left to consider the case in which $r_{j}<r_{i} \leq r_{j}+c$. From (iii) below, ${ }^{30}$ we know that in any equilibrium the IPC is satisfied; from (ii.a) above, we know that in any equilibrium there is no lending abroad. Therefore, in each country market clearing implies

\footnotetext{
${ }^{27}$ As banks are competitive, in equilibrium $r_{i}^{f}=r_{i}^{d}=r_{i}$.

${ }^{28}$ Note that, when $P$ is exogenously given, in any optimal financial contract firm loans guarantee repayment in the next period up to $P$.

${ }^{29}$ Note that $r_{i} \leq r_{j}+c$ implies that, if $B>\frac{P}{1+r_{i}}$ then $B>\frac{P}{1+r_{j}+c}$; i.e. any firm that does not have access to sufficient domestic funds to undertake the project, cannot have access to sufficient foreign funds to undertake the project.

${ }^{30}$ It is possible to use the proof of Lemma 1 (iii) here, given that it does not rely on any statement proved in Lemma 1 (ii.b).
} 
that the equilibrium interest rate moves so as to equal the domestic supply of funds to the domestic demand for funds. Suppose that both economies are in equilibrium and $r_{i}>r_{j}$. As $P$ and $L$ are equal, the supply of funds in county $i$ equals $S\left(L, r_{i}\right)=L+\int_{P /\left(1+r_{i}\right)}^{I}(I-B) d F(B)$ and must be strictly larger than the supply of funds in country $j, S\left(L, r_{j}\right)=L+\int_{P /\left(1+r_{j}\right)}^{I}(I-B) d F(B)$. At the same time, the demand for funds in county $i$ equals $D\left(L, r_{i}\right)=\int_{0}^{P /\left(1+r_{i}\right)} B d F(B)$ and must be strictly smaller than the demand for funds in country $j, D\left(L, r_{j}\right)=\int_{0}^{P /\left(1+r_{j}\right)} B d F(B)$. But then, if the market for funds is in equilibrium in country $j$, it cannot be in equilibrium for country $i$, and vice versa: which is a contradiction. Therefore, in any equilibrium we must have that $r_{R}=r_{S}=r$, $\forall L$.

(iii) From (ii.a), we know that in any equilibrium firms do not borrow from foreign banks. This condition, together with the assumption that banks are perfectly competitive, implies that the equilibrium lending rate must be equal to the equilibrium deposit rate. This allows us to simplify the IPC as follows:

$$
X_{1}\left[\gamma+(1-\gamma) \frac{Y}{P}\right]+X_{2}(1-\gamma) \geq I(1+r)\left[\gamma+(1-\gamma) \frac{Y}{P}\right]
$$

This condition defines a threshold $\bar{r}$ in the interest rate on deposits above which firms do not find profitable to undertake the project. Notice that $\bar{r}$ is independent of $B$ : either the IPC is satisfied for all firms, or it is satisfied for no firm. Suppose that $r>\bar{r}$ : all firms deposit their initial wealth in the domestic banks. Even if the central bank liquidity injection is at minimum level, $L=0$, the total supply of funds is strictly positive and equal to $\int_{0}^{I}(I-B) d F(B)>0$. However, the private demand for funds is null and, as $r>0$, also governments' effective demand for funds is null. But then the market for funds does not clear, and the interest rate must move down. Suppose instead that $L>0$ : this increases further the supply of funds, which still faces a null demand, hence the same argument applies. Then, it must be that in any equilibrium $r \leq \bar{r}$, which implies that the IPC is always satisfied.

(iv) Suppose that the claim is incorrect. Then, there must be $L_{1}>L_{0}$ such that $r\left(L_{1}\right)=$ $r\left(L_{0}\right)=\hat{r}>0$. Equal interest rate implies that $D\left(L_{0}\right)=D\left(L_{1}\right)=\int_{0}^{P /(1+\hat{r})} B d F(B)$. In any equilibrium the market for funds clears. Then, both

and

$$
S\left(L_{0}\right)=L_{0}+\int_{P /(1+\hat{r})}^{I}(I-B) d F(B)=\int_{0}^{P /(1+\hat{r})} B d F(B),
$$

$$
S\left(L_{1}\right)=L_{1}+\int_{P /(1+\hat{r})}^{I}(I-B) d F(B)=\int_{0}^{P /(1+\hat{r})} B d F(B),
$$

must be satisfied in equilibrium. But this is not possible, given that $L_{1}>L_{0}$ implies that:

$$
L_{1}+\int_{P /(1+\hat{r})}^{I}(I-B) d F(B)>L_{0}+\int_{P /(1+\hat{r})}^{I}(I-B) d F(B) .
$$

Then, either in the first case (in which the liquidity injected is $L_{1}$ ) there is excess supply, which leads to a reduction in the interest rate at a level $r<\hat{r}$; or in the second case (in which the liquidity injected is $L_{0}$ ) there is excess demand, which leads to an increase in the interest rate at a level $r>\hat{r}$. Then, for any $L_{1}>L_{0}$, we must have that $r\left(L_{1}\right)<r\left(L_{0}\right)$ unless $r=0$. This also implies that there must be an $L_{\max }$ such that $r\left(L_{\max }\right)=0$. 


\section{Proof of Proposition 1}

Holding the results stated in Lemma 1, the benchmark model economy (i.e. when $\delta=0$ ) corresponds to a multi-country version of the closed economy described in Benmelech and Bergman (2012); as in their setup, the shape of the asset pricing function $\mathbf{P}(\sigma)$, evaluated at a zero lending rate, determines whether the economy will be in a 'conventional' or in a 'credit trap' equilibrium. This is described in the following Lemma.

Lemma A1 Existence and characterisation of the equilibrium on the market for liquidated assets.

Proof. Denote by $\underline{B}^{*}$ the vector of the marginal firms which borrows in equilibrium in each country, by $\underline{r}^{*}$ the vector of the equilibrium lending rates, and by $P^{*}$ the equilibrium price of asset. The market clearing requirement in the Equilibrium Definition implies that, in any equilibrium, $P^{*}=\mathbf{P}\left(\underline{B}^{*}, \underline{r}^{*}\right)$. As for any possible asset liquidation value $P$ and liquidity injection $L$, there exist associated equilibrium lending rate $r^{*}$ and equilibrium marginal borrowing firm $B^{*}$ (Lemma 1), then for any $P$ and $L$ it is possible to define $\underline{r}^{*}(P, L)$ and $\underline{B}^{*}(P, L)$, and, for any direct pricing function $P(B, r)$ an indirect pricing function as follows:

$$
p(P, L) \equiv \mathbf{P}\left(\underline{B}^{*}(P, L), \underline{r}^{*}(P, L)\right) .
$$

In terms of the indirect pricing function, market clearing implies that, in any equilibrium, $p\left(P^{*}, L\right)=$ $P^{*}$.

Define $\bar{B}(L)$ as the value representing the marginal firm that obtain financing assuming that the whole liquidity injected is lent to firms. ${ }^{31}$ Benmelech and Bergman (2012), p. 3018 ss., show that, for any level of liquidity injected $L \leq \int_{0}^{I} B d F(B)$, the indirect pricing function $p(P, L)$ is increasing in $P$ over the region $P<\bar{B}(L)$ and decreasing in $P$ over the region $P>\bar{B}(L)$; moreover, the function $\mathbf{P}(P, 0)$, which is the direct pricing function at a zero lending rate and a marginal borrowing firm $B=P$, serves as an envelope of $p(P, L)$ - i.e. the two functions coincide up to $\bar{B}(L)$, while, for $P>\bar{B}(L), \mathbf{P}(P, 0)$ is increasing in $P$ and $p(P, L)$ is decreasing in $P$. These properties allow to illustrate the possible equilibria emerging in the market for liquidated assets as in Figure 4.

The equilibrium asset price is bounded from above by $Y$, as firms buying assets will never bid above the asset return in the next period. Therefore, an equilibrium is a point at which the indirect pricing function crosses the $45^{\circ}$ line, i.e. $p\left(P^{*}, L\right)=P^{*}$, granted that $P^{*} \leq Y$. The shape of the asset pricing function evaluated at a zero lending rate, $\mathbf{P}(P, 0)$, determines whether the economy will be in a 'conventional' or in a 'credit trap' equilibrium.

If $\mathbf{P}(P, 0)$ crosses the $45^{\circ}$ line at a value $\bar{P} \geq Y$, then a sufficient injections of liquidity, $L_{\max }$, will enable an equilibrium in which the asset price reaches its full value $Y$. In this case, sufficient liquidity injections will enable maximum possible lending, $\int_{0}^{Y} B d F(B)$, and the economy is in a conventional equilibrium. By contrast, if $\mathbf{P}(P, 0)$ crosses the $45^{\circ}$ line at a value $\bar{P}<Y$, then there is a liquidity level $L^{\prime}$ beyond which any additional liquidity injection does not affect lending, and the asset price cannot exceed the level $\bar{P}, \forall L$. This is shown in the right panel of Figure 4 , in which the indirect pricing function $p\left(P, L_{2}\right)$ cannot lead to any equilibrium such that $P^{*}>\bar{P}$, and banks will not increase lending beyond $\int_{0}^{\bar{P}} B d F(B)<\int_{0}^{Y} B d F(B)$, regardless of any additional liquidity injection. This is defined as a credit trap equilibrium.

\footnotetext{
${ }^{31}$ From Lemma 1 we know that, if $\delta=0$, then for $\forall P$ in equilibrium no variable displays difference across countries; hence, in the following, it is possible to drop country indices without loss of generality.
} 

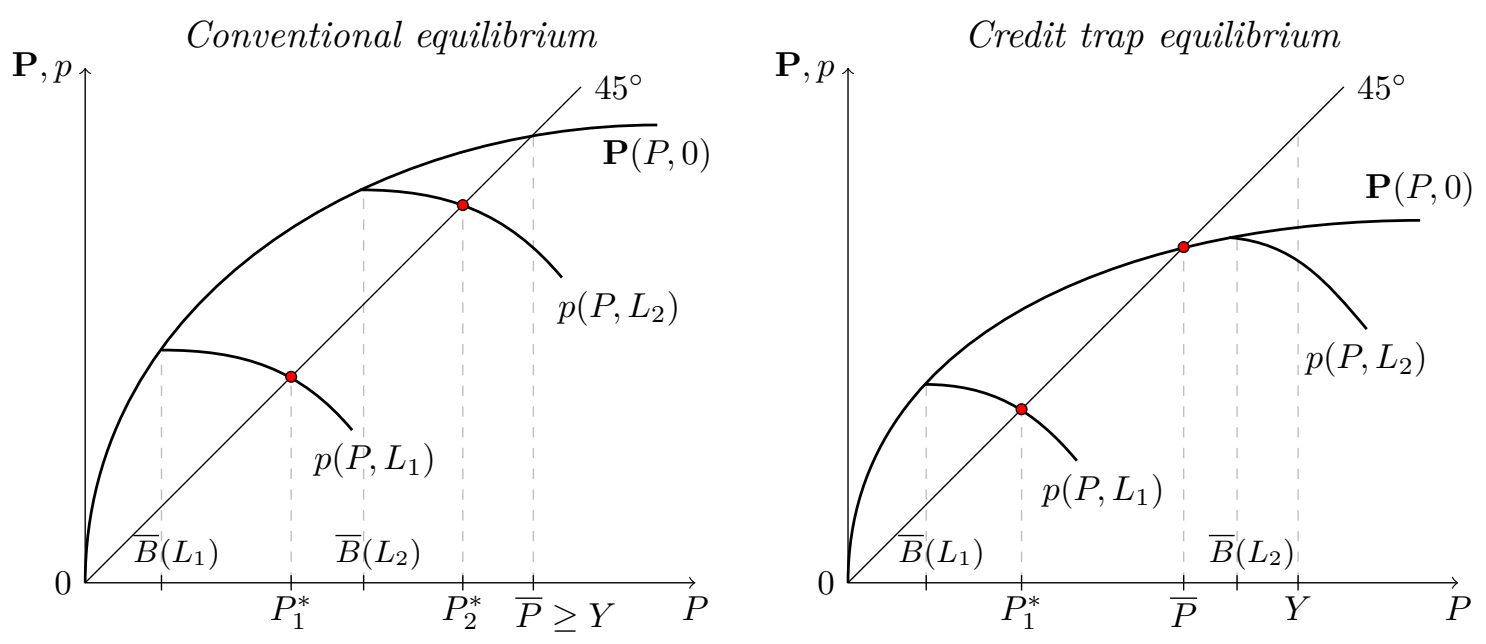

Figure 4: Equilibrium on the Market for Liquidated Assets

Note that, if the pricing function $\mathbf{P}(P, 0)$ satisfies the following condition:

$$
\begin{aligned}
\exists P^{\prime}: & \mathbf{P}(P, 0)>P, \forall 0<P<P^{\prime} \text { and } \\
& \mathbf{P}\left(P^{\prime}, 0\right) \geq P^{\prime} \text { and } \\
& \mathbf{P}(P, 0)<P \text { only if } P>P^{\prime},
\end{aligned}
$$

then any increase in liquidity will produce, continuously, an increase in the liquidation price of assets $P^{*}$, until $P^{*}=\bar{P}$ if the economy is in a credit trap, or until $P^{*}=Y$ if the economy is in a conventional equilibrium. By contrast, if condition (21) is not satisfied, the pricing function $\mathbf{P}(P, 0)$ can display multiple fixed points; in this case, there can be intervals in $L$ within which liquidity variations do not affect $P^{*}$, and outside which liquidity variations do affect $P^{*}$.

In the framework described in Section 2, the pricing function evaluated at a zero lending rate is given by:

$$
\mathbf{P}(P, 0)=\min \left\{\frac{Q(P, 0)}{\gamma_{R}+\gamma_{S}}, Y\right\}
$$

where $Q(P, 0)$ is given by:

$$
\begin{aligned}
Q(P, 0) & =\sum_{i}\left(1-\gamma_{i}\right)\left[\int_{0}^{P}\left(X_{1}-B\right) d F(B)+\int_{P}^{I}(I-B) d F(B)\right] \\
& =2(1-\gamma)\left[\left(X_{1}-I\right) F(P)+E(A)\right],
\end{aligned}
$$

where $\gamma \equiv \frac{\gamma_{R}+\gamma_{S}}{2}$ is the cross-country average of the liquidity shocks hitting firms at time-1, $E(A) \equiv \int_{0}^{I}(I-B) d F(B)$ is the aggregate time- 0 wealth, and $F(P)$ is the fraction of the population obtaining financing at time-0, multiplied by $X_{1}-I$, which is the additional time-1 wealth due to the project.

Plugging (23) into (22) (and ignoring the min operator, consistently with the function $\mathbf{P}(P, 0)$ shown in Figure 4), we obtain:

$$
\mathbf{P}(P, 0)=\frac{1-\gamma}{\gamma}\left[\left(X_{1}-I\right) F(P)+E(A)\right] .
$$

Note that all terms in the right hand side of equation (24) are constant in $P$, apart from $F(P)$. This implies that the distribution function of the firms' wealth $F$ determines the shape of the direct pricing function $\mathbf{P}(P, 0)$, and thus whether it satisfies condition (21). A concave $F$, for 
instance, guarantees that for any aggregate firms' wealth $E(A)$ and liquidity shock $\gamma$, condition (21) is fulfilled and liquidity injections continuously affect the liquidation price of asset. ${ }^{32}$ However, the results stated in Propositions 1 to 3 hold regardless of whether condition (21) is satisfied.

Now we return to the proof of Proposition 1.

(i) Equation (24) increases as $\gamma$ decreases, and approaches infinity as $\gamma$ approaches 0 . But then, for any distribution function $F$ and time-0 aggregate wealth $E(A)$, a sufficiently small value of $\gamma$ implies that there is a $P^{\prime}>Y$ such that the following holds: $\mathbf{P}\left(P^{\prime}, 0\right) \geq P^{\prime}$. But then, as for a given $L$ we have that $p(P, L)$ coincides with $\mathbf{P}(P, 0)$ up to $P=\bar{B}(L)$ and is decreasing in $P$ beyond, there must be an $L^{\prime}$ such that $p\left(P^{*}, L^{\prime}\right)=P^{*}$ exactly for $P^{*}=Y$. As from Lemma 1 a sufficiently forceful liquidity injections leads to a zero lending rate, then there exists a level $L_{\max }$ at which the asset price satisfies $P^{*}=Y$ and corporate lending is at the maximum level, $\int_{0}^{Y} B d F(B)$.

(ii) Equation (24) decreases as $\gamma$ increases, and approaches 0 as $\gamma$ approaches 1. But then, for any distribution function $F$ and time-0 aggregate wealth $E(A)$, a $\gamma$ sufficiently large implies that there is a $P^{\prime}<Y$ such that $\mathbf{P}(P, 0)<P$ for the whole interval $\left[P^{\prime}, Y\right]$. As we know that $p(P, L)$ is bounded from above by $\mathbf{P}(P, 0), \forall P$, then at any point in which $p\left(P^{*}, L^{\prime}\right)=P^{*}$, it must be that $P^{*} \leq P^{\prime}$. Therefore, $P^{*}<Y, \forall L$, and, even if total liquidity is sufficiently large to lead to a zero lending rate, the collateral constraint prevents corporate lending from increasing beyond the level $\int_{0}^{P^{\prime}} B d F(B)$, which is strictly lower than $\int_{0}^{Y} B d F(B)$.

(iii) As there is one market for firms' assets in the monetary union, the law of one price implies that, for any $L$, any equilibrium price of assets $P^{*}$ is equal across countries. Hence, in any country $i$, total lending in equilibrium will be equal to $\int_{0}^{P^{*} /\left(1+r_{i}^{*}\right)} B d F(B)$. From Lemma 1 (ii), we have that, regardless of differences in sovereign default risk, $\rho_{i}$, for any $L$ the equilibrium interest rate is equal across countries, $r_{i}^{*}=r_{j}^{*}=r^{*}$. Then, for any $L$, the amount of total lending in each country coincide and is equal to $\int_{0}^{P^{*} /\left(1+r^{*}\right)} B d F(B)$. Therefore, it is possible to conclude that a liquidity injection always produces equal effects in both countries.

\section{Proof of Lemma 2}

It is trivial to prove that, when the asset price is stochastic, firms with borrowing requirement $B \leq \frac{P_{l}(L)}{1+r^{f}}$ can still borrow and invest. Then, suppose that the relevant collateral-in-advance constraint is not $B \leq \frac{E(P)}{1+r^{f}}$ but $B \leq \frac{P_{l}(L)}{1+r^{f}}$. But then there will be firms with $B>\frac{P_{l}(L)}{1+r^{f}}$ that banks would find profitable to lend to, by offering a financial contract so specified. At time- 0 , the firm obtain funds $B_{e}$, with

$$
B_{e}>\frac{P_{l}(L)}{1+r^{f}}
$$

At time-1, if the equilibrium price of the asset is $P_{l}(L)$, the firm repays exactly $P_{l}(L)$; if the equilibrium price of the asset is $P_{h}(L)$, the firm repays $\left(1+r^{e}\right) B_{e} \leq P_{h}(L)$, where $r^{e}$ satisfies:

$$
r^{e} \geq \frac{1}{1-\eta}\left(1+r^{f}-\eta \frac{P_{l}(L)}{B_{e}}\right)-1
$$

\footnotetext{
${ }^{32}$ On the contrary, a strictly convex $F$ and a sufficiently low level of firms' initial wealth $E(A)$ would lead to a different equilibrium class that Benmelech and Bergman (2012), p. 3019 ss., define as "jump start" equilibrium.
} 
Note that this contract is incentive compatible from the firm's viewpoint, as it specifies in both future states of the world repayments that do not exceed the price of asset. Moreover, this contract is profitable from the bank's viewpoint, as its expected return is greater or equal than the expected return on loans with $B \leq \frac{P_{l}(L)}{1+r^{f}}$. This is because, if the relationship (25) holds, then it must also hold:

$$
\frac{\eta P_{l}(L)+\left(1+r^{e}\right)(1-\eta) B_{e}}{B_{e}} \geq 1+r^{f},
$$

where the left hand side is the time- 0 expected return on the financial contract specified above, and the right hand side is the time-0 expected return on a loan with $B \leq \frac{P_{l}(L)}{1+r^{f}}$.

This shows that, in equilibrium, firms with $B>\frac{P_{l}(L)}{1+r^{f}}$ can borrow and invest, so the relevant collateral-in-advance constraint must specify a threshold greater than $\frac{P_{l}(L)}{1+r^{f}}$.

To obtain the collateral-in-advance constraint, we must identify the firm with the highest borrowing requirement that can be fulfilled in an optimal financial contract. We know that, contingent on the good state of the world realizing, the maximum repayment equals $P_{h}(L)$. Therefore, we can plug the value for $r^{e}$ obtained in equation (25), holding with equality, into $\left(1+r^{e}\right) B_{e}=P_{h}(L)$, to obtain:

$$
B_{e}=\frac{1}{1-r^{f}}\left[(1-\eta) P_{h}(L)+\eta P_{l}(L)\right]=\frac{E(P)}{1+r^{f}} .
$$

This proves that the relevant collateral-in-advance constraint for the stochastic case is given by:

$$
B \leq \frac{E(P)}{1+r^{f}}
$$

\section{Proof of Lemma 3}

(o) We prove that the IPC described by the condition (16) relaxes as $B$ reduces, i.e. if $B_{0}<B_{1}$, then

$$
\begin{aligned}
& B_{0}<B_{1} \Rightarrow \\
& \text { l.h.s. }\left(16 \mid B=B_{0}\right)-\text { r.h.s. }\left(16 \mid B=B_{0}\right)>\text { l.h.s. }\left(16 \mid B=B_{1}\right)-\text { r.h.s. }\left(16 \mid B=B_{1}\right) .
\end{aligned}
$$

Provided that (16) is differentiable in $B$, a sufficient condition for (26) to be true is given by:

$$
\begin{aligned}
& \frac{\partial \text { l.h.s. }(16)}{\partial(-B)}>\frac{\partial \text { r.h.s. }(16)}{\partial(-B)} \\
\Leftrightarrow & \frac{\partial \text { l.h.s. }(16)}{\partial(-B)}=\left(1+r_{i}^{f}\right)\left[\gamma+(1-\gamma) Y E\left(\frac{1}{P}\right)\right] \\
& >\frac{\partial \text { r.h.s. }(16)}{\partial(-B)}=\left(1+r_{i}^{d}\right)\left[\gamma(1-\delta \rho(1-\alpha))+(1-\gamma)\left((1-\delta \rho) Y E\left(\frac{1}{P}\right)+\alpha \delta \rho\right)\right] \\
\Leftrightarrow & \left\{\frac{1+r_{i}^{f}}{1+r_{i}^{d}}\right\}\left\{\frac{\gamma+(1-\gamma) Y E\left(\frac{1}{P}\right)}{\gamma[1-\delta \rho(1-\alpha)]+(1-\gamma)\left[(1-\delta \rho) Y E\left(\frac{1}{P}\right)+\alpha \delta \rho\right]}\right\} \geq 1 \\
\Leftrightarrow & r_{i}^{f} \geq r_{i}^{d} \text { and } \gamma(1-\alpha)+(1-\gamma)\left[Y E\left(\frac{1}{P}\right)-\alpha\right]>0 .
\end{aligned}
$$

Both these conditions are satisfied in equilibrium. First, the lending rate is equal to the deposit rate for all firms with borrowing requirement up to $P_{L}(l)$, and greater than the deposit rate for those firms possibly obtaining loans exceeding $P_{L}(l)$. Second, the return on the asset cannot be smaller than its price in expectations, i.e. $Y E\left(\frac{1}{P}\right)>1$, while $\alpha<1$ by assumption.

This proves that equation (17) defines a threshold $\bar{r}_{i}^{f}$ such that, if $r_{i}^{f} \leq \bar{r}_{i}^{f}$, then the IPC is satisfied for all firms. 
(i) Market clearing implies that, in each country, there are at least some firms for which the IPC is satisfied (see Lemma 1). If $r_{i}^{f} \leq \bar{r}_{i}^{f}$, we know that the IPC is satisfied for all firms. ${ }^{33}$ If $r_{i}>\bar{r}_{i}$, it is possible that the IPC is satisfied for those firms with borrowing requirement smaller than or equal to a certain threshold, $\tilde{B}$, and it is not for all the others. Suppose that $r_{i}>\bar{r}_{i}$ and there are some firms for which the IPC is not satisfied. In this case, the marginal borrowing firm must have a borrowing requirement $B=\min \left(\frac{P}{1+r_{i}}, \tilde{B}\right)$. Hence, the total supply of funds is equal to:

$$
S\left(L, r_{i}\right)=L+\int_{\min \left(\frac{P}{1+r_{i}}, \tilde{B}\right)}^{I}(I-B) d F(B) .
$$

As by assumption $\bar{r}_{i}>\frac{\delta \rho_{R}}{1-\delta \rho_{R}}$, and $r_{i}>\bar{r}_{i}$, then $r_{i}>\frac{\delta \rho_{R}}{1-\delta \rho_{R}}$. This implies that firm loans grant a higher expected return than sovereign debt; then banks do not lend funds to governments. Thus, the total demand for funds is equal to:

$$
D\left(L, r_{i}\right)=\int_{0}^{\min \left(\frac{P}{1+r_{i}}, \tilde{B}\right)} B d F(B) .
$$

As the right hand side of condition (16) is increasing in the interest rate, the level of borrowing requirement $\tilde{B}$ must decrease as the interest rate reduces. As the aggregate liquidity increases, the supply of funds raises and the interest rate moves down. At a certain liquidity level $\hat{L}$ the interest rate eventually reaches $\bar{r}_{i}$, for which the IPC is satisfied for all firms. As $\underline{L}$ is defined as the aggregate liquidity level at which the interest rate reaches $\frac{\delta \rho_{R}}{1-\delta \rho_{R}}$, and by assumption $\bar{r}_{i}>\frac{\delta \rho_{R}}{1-\delta \rho_{R}}$, then it must be that $\hat{L}<\underline{L}$.

(ii) From (i) we know that $\underline{L}$ is the threshold at which $r_{R}=\frac{\delta \rho_{R}}{1-\delta \rho_{R}}$, and for $L<\underline{L}$ we have that $r_{R}>\frac{\delta \rho_{R}}{1-\delta \rho_{R}}$. Then, for any $L \leq \underline{L}$, as firm loans grant a higher expected return than sovereign bonds, banks do not lend funds to government. Thus, Lemma 1 (ii) still applies, and an increase in $L$ up to $\underline{L}$ reduces the equilibrium interest rate, which must be equal in both countries.

(iii) From (i) and (ii), as $L$ reaches the threshold $\underline{L}$, the lending rate in both countries equals $\frac{\delta \rho_{R}}{1-\delta \rho_{R}}$. At this level, country $R$ 's banks obtain the same expected return lending to firm and underwriting domestic sovereign bonds, which pay a nominal yield $r_{R}^{g}=\frac{\rho_{R}}{1-\rho_{R}}$. Indeed, when $\delta>0$, the banks' profit maximisation problem implies that country $R$ 's banks prefer to lend to firms only if the following condition is satisfied:

$$
r_{R}>\frac{\left(1-\rho_{R}\right) r_{R}^{g}-\rho_{R}(1-\delta)}{1-\delta \rho_{R}} .
$$

Despite increases in $L$, as long as foreign investors hold a positive amount of sovereign debt, the yield paid by country $R$ 's government bonds remains constant at the level $r_{R}^{g}=\frac{\rho_{R}}{1-\rho_{R}}$; hence, no arbitrage implies that the lending rate does not reduce and remain constant in $L$ at $r_{R}=\frac{\delta \rho_{R}}{1-\delta \rho_{R}}$ (as shown in Figure 3 above). Constant the lending rate, the collateral constraint does not relax. This implies that country $R$ 's banks invest any additional fund injected beyond $\underline{L}$ into purchases of domestic sovereign bonds. As the total liquidity level reaches a certain threshold $\bar{L}$, the whole supply of sovereign debt is purchased by domestic banks. Beyond $\bar{L}$, a further increase in the supply of funds faces an unchanged demand for funds, given that banks cannot purchase more units of domestic sovereign debt from international investors. Hence, if $L>\bar{L}$, market clearing implies that liquidity injections regain effectiveness in country $R$, reducing both the sovereign yield and the lending rate, relaxing the collateral constraint and allowing further increases in corporate

\footnotetext{
${ }^{33}$ Perfect competitive banks imply that $r_{i}^{f}=r_{i}^{d}=r_{i}$ in equilibrium, which will be used hereinafter.
} 
lending. If $\rho_{S}=0$, this mechanism generating a flat region in the lending rate does not apply in country $S$; it straightforward to verify that it does apply otherwise, in a similar manner as the one described for country $R$. Nevertheless, as long as the sovereign default risks are cross-country different, the flat region and the following credit trap will emerge for different liquidity levels in the two countries; ${ }^{34}$ hence, even in this case lending responses will remain asymmetric across countries, and the claim in (iii) still holds.

(iv) The claim concerning the effects of increases in $\delta$ and/or $\rho$ is trivially implied by the arguments provided in (i-iii) above. $[\underline{L}, \bar{L}]$ is exactly equal to the amount of sovereign debt supplied $G_{R}$ only if the marginal cost on foreign lending $c$ is sufficiently large; it is smaller than $G_{R}$ otherwise. Indeed, the possibility of cross-border lending implies that, in equilibrium, cross-country differences in the lending rate must lie in the interval $[-c, c]$. Suppose they do not, and specifically that $r_{R}>r_{S}+c$. But then, there will be no demand for those funds supplied by country $R$ 's banks, and by market clearing interest rates adjust such that $r_{R}=r_{S}+c$.

Robustness: Allowing firms not to deposit initial wealth In the full model, the risk of bank bankruptcy may rise the firm's incentive not to deposit funds in the bank, so as to have them available to purchase liquidated asset at time-1. For simplicity, the setup described in Section 2 does only allow firms to choose between undertaking the project and depositing their wealth in the banks. Suppose instead that, in an otherwise unaltered setup, those firms which do not undertake the project can freely choose how much of their initial wealth to deposit, $a \in[0, A]$. The linearity of the maximisation problem implies a corner solution, then it must be either $a^{*}=A$ or $a^{*}=0 .{ }^{35}$ The time- 0 expected payoff from choosing $a=A$ is given by the right hand side of equation (16), while the one from choosing $a=0$ equals $\gamma_{R}(I-B+P)+\left(1-\gamma_{R}\right)\left[(I-B) Y E\left(\frac{1}{P}\right)+X_{2}^{\prime}\right]$. Rearranging terms, $a^{*}=A \Leftrightarrow$

$$
r_{R} \geq\left[1-\delta \rho_{R}+\frac{\alpha \delta \rho_{R}}{\gamma_{R}+\left(1-\gamma_{R}\right) Y E\left(\frac{1}{P}\right)}\right]^{-1}-1 .
$$

This condition fixes a possibly greater than zero lower bound for the interest rate in country $R$. Indeed, suppose that there is an equilibrium with the interest rate below this bound: private deposits dry up and, by market clearing, the interest rate increases until this bound is reached. However, the maximum possible value of this lower bound, which is reached for $P \rightarrow 0$, is bounded from above by $\frac{\delta \rho_{R}}{1-\delta \rho_{R}}$. This implies that, even in this modified setup, all the results described in Lemma 3 apply unchanged; the only difference consists in the fact that, beyond $\bar{L}$, country $R$ 's interest rate does not converge to zero as $L$ increases (as shown in Figure 3); it converges instead to a value possibly greater than zero, but still smaller than $\frac{\delta \rho_{R}}{1-\delta \rho_{R}}$.

\section{Proof of Proposition 2}

In the following, I provide the complete proof for the case in which $\rho_{R}>\rho_{S}=0$. Provided the statements in the proof of Lemma (ii), the arguments extend in a straightforward manner to the more general case in which $\rho_{R}>\rho_{S} \geq 0$.

\footnotetext{
${ }^{34}$ Specifically, the credit trap region begins for a lower liquidity level in the country suffering from a higher risk of sovereign default.

${ }^{35}$ If the corner solutions lead to the same expected payoff, then $a^{*} \in[0, A]$.
} 
(i) From Lemma 3 we know that, in country $S$, injections of liquidity continuously reduce the lending rate until the zero-bound. This boosts lending by increasing the discounted price of collateral through reductions in the denominator of $\frac{E_{S}(P)}{1+r_{S}}$. Moreover, as in equilibrium the project is more profitable than deposits, a higher amount of lending at time-0 will increase $Q\left(B_{S}, r_{S}\right)$ at time-1, possibly boosting the expected liquidation price of collateral. In this case, time-0 lending expands further, given that the collateral constraint relaxes further due to increases in the numerator of $\frac{E_{S}(P)}{1+r_{S}}$. As liquidity is injected, corporate lending can reach the maximum possible level, or it can results being constrained at a sub-optimal level (see Proposition 3). In both cases, however, any central bank liquidity injection has always a positive effect on lending through at least the interest rate channel above described, until the lending rate reaches the zero-bound. Note that, as banks in country $S$ are exposed to a zero sovereign default probability, they correctly internalise sovereign risks; hence, until the lending rate reaches the zero-bound, they neither underwrite domestic sovereign debt nor foreign one. ${ }^{36}$ This implies that the whole liquidity injected by the central bank is lent out to firms. Moreover, unless the lending rate spread is larger than the cost of foreign lending, $c$, none of these funds are lent to firms in country $R$.

(ii) For an initial liquidity range, $\left[0, L^{\prime}\right]$, loans are more profitable than sovereign debt to country $R$ 's banks, and liquidity injections reduce the lending rate, thus boosting corporate lending in country $R$ as described in (i). However, beyond the liquidity threshold $L^{\prime}$ and for the whole interval $\left[L^{\prime}, L^{\prime \prime}\right],{ }^{37}$ the lending rate is constant in $L$ and equal to $\frac{\delta \rho_{R}}{1-\delta \rho_{R}}$. As explained in more details in Lemma 3 , banks perceive domestic sovereign debt as granting a net yield equal to $\frac{\delta \rho_{R}}{1-\delta \rho_{R}}$; hence, despite further liquidity injections, by no arbitrage the interest rate on loans cannot reduce until sovereign debt is available. This implies that the denominator of $\frac{E_{R}(P)}{1+r_{R}}$ remains constant i.e. the collateral constraint does not relax, at least through the interest rate channel - and the liquidity injected is used by banks to underwrite domestic sovereign bonds. Liquidity injections further relax the collateral constraint through the interest rate channel only beyond $L^{\prime \prime}$, threshold at which the whole stock of country $R$ 's sovereign debt is held by domestic banks (see Lemma 3).

(iii) In the interval $\left[L^{\prime}, L^{\prime \prime}\right]$, corporate lending in country $R$ can display positive responses only if a higher lending in country $S$, by increasing $Q\left(B_{S}, r_{S}\right)$, boosts the expected liquidation price of collateral. In this case the collateral constraint, constant its denominator, will still relax, thanks to an increase in the numerator of $\frac{E_{R}(P)}{1+r_{R}}$. Hence, in country $R$ part of the liquidity injected can be used by banks to increase lending even in the interval $\left[L^{\prime}, L^{\prime \prime}\right]$. Nevertheless, responses to monetary policy remain asymmetric across countries, for the following reasons: (a) this positive spillover from the safe to the risky country depends on collateral price dynamics that may not apply; (b) even if they apply, in country $R$ only part of the liquidity injected is lent to firms, while in country $S$ the whole liquidity injected is lent to firms.

(iv) Increases in both $\delta$ and $\rho_{R}$, by rising country $R$ 's sovereign yields to domestic banks, reduce the threshold $L^{\prime}$ at which liquidity injections cease to affect the interest rate in country $R$ (see Lemma 3). Concerning the implications due to the size of sovereign debt supply, recall that: $L^{\prime}$ is the value at which, in country $R$, banks start underwriting domestic sovereign debt; $L^{\prime \prime}$ is the level

\footnotetext{
${ }^{36}$ If $\rho_{S}>0$, this lower-bound will be actually larger than 0: see Lemma 3.

${ }^{37}$ The length of the interval $\left[L^{\prime}, L^{\prime \prime}\right]$ is function of the amount of country $R$ 's sovereign debt issued: see (iv) below.
} 
at which the whole stock of sovereign debt is held by domestic banks. It follows that the length of the interval $\left[L^{\prime}, L^{\prime \prime}\right]$ increases with $G_{R}$. However, from Lemma 3 we know that cross-country differences in the lending rate must lie in the interval $[-c, c]$. Therefore, the length of the interval $\left[L^{\prime}, L^{\prime \prime}\right]$ is non-decreasing in $G_{R}$, and strictly increasing in $G_{R}$ only if $c$ is sufficiently large.

\section{Proof of Proposition 3}

(i) The arguments provided in Lemma A1 can be easily generalised to take into account the fact that, with $\delta>0$, equilibrium interest rates given $L$ do not necessarily coincide across countries; then the argument provided in Proposition 1 (ii) can be still applied here to prove the existence of credit trap equilibria. ${ }^{38}$ Specifically, the asset pricing function evaluated at a zero lending rate, $\mathbf{P}(P, 0)$, decreases as $\gamma$ increases, and approaches 0 as $\gamma$ approaches 1 . But then, for any distribution function $F$ and time-0 aggregate wealth $E(A)$, a $\gamma$ sufficiently large implies that there is a $P^{\prime}<Y$ such that $\mathbf{P}(P, 0)<P$ for the whole interval $\left[P^{\prime}, Y\right]$. As we know that $p(P, L)$ is bounded from above by $\mathbf{P}(P, 0), \forall P$, then at any point in which $p\left(P^{*}, L^{\prime}\right)=P^{*}$, it must be that $P^{*} \leq P^{\prime}$. Therefore, $P^{*}<Y, \forall L$, and, even if total liquidity is sufficiently large to lead to a zero lending rate in both countries, the collateral constraint prevents corporate lending from increasing beyond the level $\int_{0}^{P^{\prime}} B d F(B)$, which is strictly lower than $\int_{0}^{Y} B d F(B)$.

(ii) From (i) we know that the level of the asset pricing function evaluated at a zero lending rate, $\mathbf{P}(P, 0)$, determines whether $P^{*}$ will be constrained at levels strictly lower than $Y$, for any $L$. Let us analyze the market for liquidated assets when $\delta>0$, conditional on sovereign default occurring at time-1, and compare it with the benchmark case. Specifically, let us compare the liquidity available to firms purchasing assets when $\delta>0, Q(\underline{B}, 0 \mid \text { sdef }=1)_{\delta>0}$, with the quantity available when $\delta=0, Q(\underline{B}, 0 \mid \text { sdef }=1)_{\delta=0}$. At a zero lending rate, given $\underline{B}$, we have that:

$$
Q(\underline{B}, 0 \mid \operatorname{sdef}=1)_{\delta>0}=Q(\underline{B}, 0 \mid \operatorname{sdef}=1)_{\delta=0}-\delta \int_{\underline{B}}^{I}(I-B) d F(B) .
$$

As by assumption $Y<I$, we have that, for any $\underline{B}$ :

$$
\delta \int_{\underline{B}}^{I}(I-B) d F(B)>0 .
$$

This implies that $Q(\underline{B}, 0 \mid \text { sdef }=1)_{\delta>0}$ is strictly smaller than $Q(\underline{B}, 0 \mid \text { sdef }=1)_{\delta=0}$ for any $\underline{B}$.

Now, define $\Gamma$ as the set of values of $\gamma$ implying that the benchmark economy is in a conventional equilibrium. This means that, for some $L$, these $\gamma$ lead to a time-1 total liquidity, $\tilde{Q}(\underline{B}, \underline{r})$, such that:

$$
P^{*}=\mathbf{P}(\underline{B}, \underline{r} \mid \forall \text { sdef })=\min \left(\frac{\tilde{Q}(\underline{B}, \underline{r})}{\gamma}, Y\right)=Y .
$$

Given that $\frac{\partial \mathbf{P}(P, 0)}{\partial \delta}$ is well-defined and negative $\forall 0<\delta<1$, and given that $Q(\underline{B}, 0 \mid \text { sdef }=1)_{\delta>0}$ is strictly smaller than $Q(\underline{B}, 0 \mid \text { sdef }=1)_{\delta=0}$ for any $\underline{B}$, then there must be a non-empty subset of $\Gamma, \Gamma^{\prime} \subseteq \Gamma$ such that, for $\gamma \in \Gamma^{\prime}$, conditional on sovereign default occurring in country $i$ at time-1, in the 'sovereign default sock' scenario:

$$
P^{*}=\mathbf{P}(\underline{B}, \underline{r} \mid \operatorname{sdef}=1)=\min \left(\frac{Q(\underline{B}, \underline{r} \mid \operatorname{sdef}=1)}{\gamma}, Y\right)=\frac{Q(\underline{B}, \underline{r} \mid \operatorname{sdef}=1)}{\gamma}<Y, \forall L,
$$

while, by construction, in the benchmark economy $P^{*}=Y$ in this state of the world.

\footnotetext{
${ }^{38}$ Simmetrically, the argument in Proposition 1 (i) can be used to prove the existence of conventional equilibia for the model with $\delta>0$.
} 
Country $j$ 's banks, and a share equal to $1-\delta$ of country $i$ 's banks, are not bankrupt in the time- 1 state of the world in which sovereign default occurs in country $i$. Suppose that the time-0 liquidity injection assumes an arbitrarily large value, at least sufficiently large to have that corporate lending is maximal in the benchmark economy; moreover, suppose that those banks continuing their business at time- 1 satisfied any loan demand up to $b=Y$ at time- 0 . As the liquidation price of assets in this state of the world is $P^{*}<Y$, the time- 0 expected price of assets must be also be strictly lower than $Y$. But then such banks' choices do not fulfill the collateralin-advance constraint (15), which must be satisfied in any optimal financial contract; this is a contradiction.

But then we have that, regardless of the liquidity injected at time-0, country $j$ 's banks willingness to lend funds cannot exceed the threshold:

$$
E_{j}(P)=\left(1-\rho_{i}\right) Y+\rho_{i} P^{*}<Y .
$$

Therefore, at time- 0 country $j$ 's lending cannot be maximal, $\forall L$, and we can conclude that in the 'sovereign default shock' scenario the range of values in $\gamma$ under which a credit trap equilibrium realises is larger than in the benchmark model.

(iii) An increase in $\delta$ implies a lower value of $Q(\underline{B}, 0)$; this, given the argument provided in (ii) above, enlarges the range within which a credit trap equilibrium occurs. On the other side, an increase in $\rho_{i}$ reduces $E_{j}(P)$, by increasing the probability that $P^{*}<Y$ will emerge as equilibrium price of asset in the next period (see (ii) above). 


\section{Appendix C. Supplementary Figures}
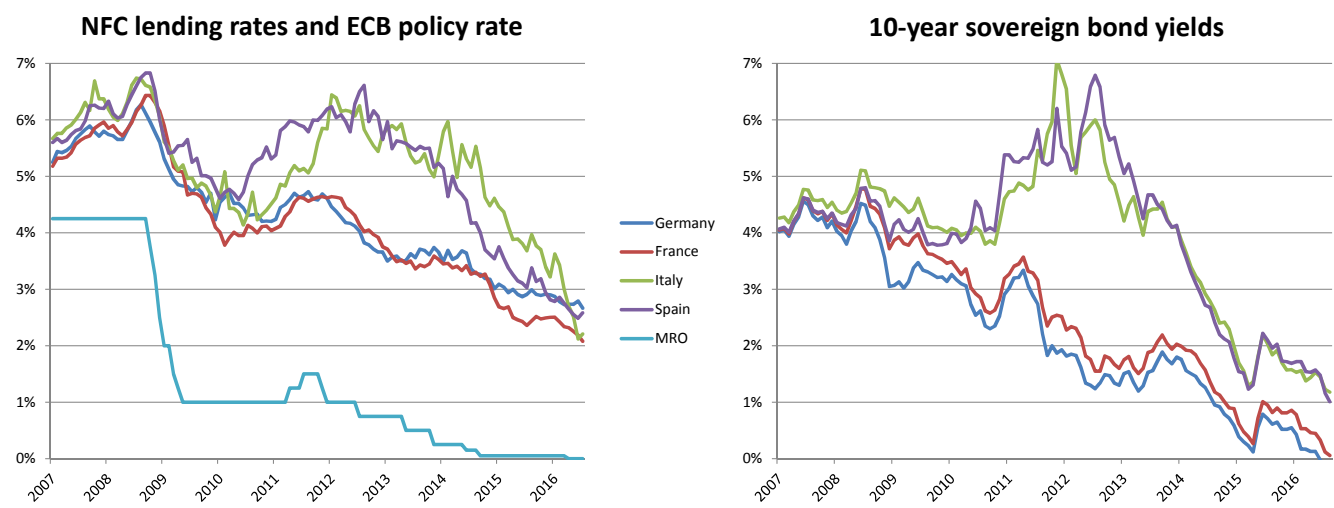

Figure 5: NFCs Lending Rates, ECB Policy Rate, and Sovereign Yields

Left panel: Lending rates to NFCs, 1-5 years maturity, up to 1 million euros, monthly, and ECB main refinancing operations rate (MRO). Right panel: 10-year sovereign bond yields, monthly. Data sources: ECB Statistical Data Warehouse, OECD.

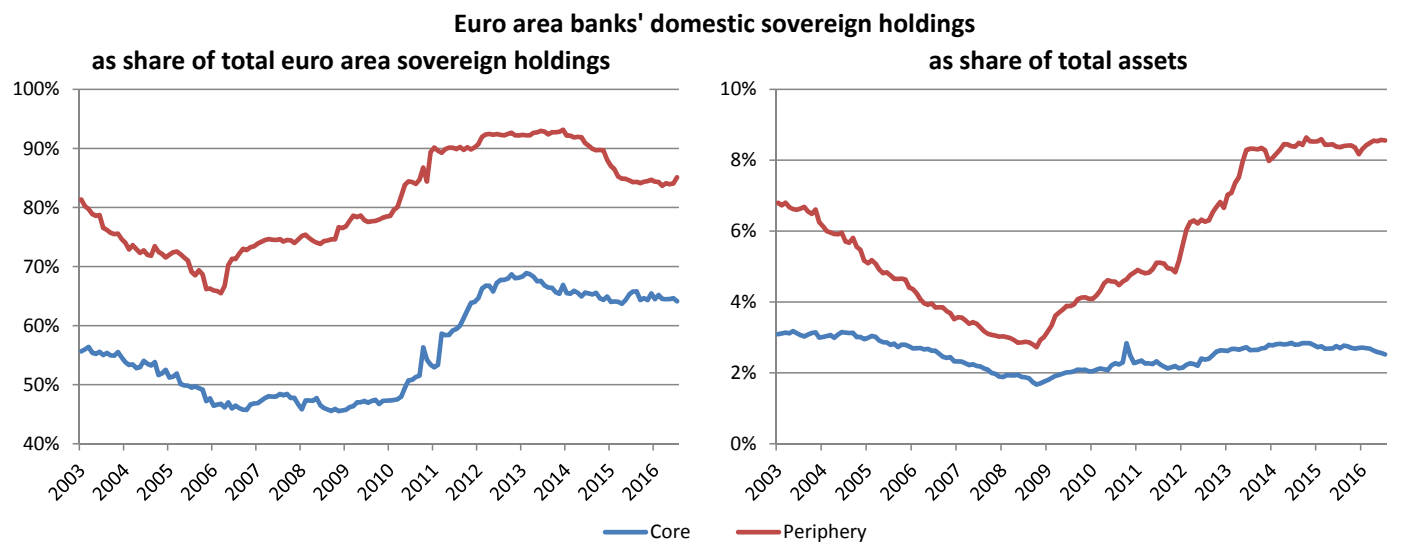

Figure 6: Domestic Sovereign Debt Holdings of Banks in the Euro Area

Monthly outstanding amounts of domestic sovereign debt holdings of banks as share of their total euro area sovereign portfolio (left panel) and as share of their total assets (right panel). Data source: ECB Statistical Data Warehouse.

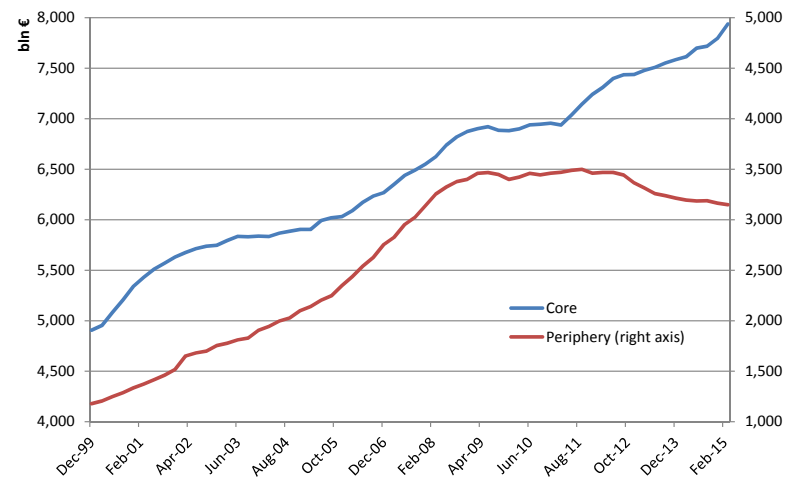

Figure 7: Total Credit to NFCs in the Euro Area

Quarterly outstanding amounts of credit, from all lending sectors, to NFCs based in core and periphery countries of the euro area. Data source: BIS. 